\title{
Nanocomposites of Conductive Polymers and Nanoparticles Deposited on Porous Material as a Strategy to Improve its Corrosion Resistance
}

C. Garcia-Cabezon ${ }^{1, *}$, C. Salvo-Comino ${ }^{2}$, Garcia-Hernandez ${ }^{2}$, M.L. RodriguezMendez $^{2}$, F.Martin-Pedrosa ${ }^{1}$.

${ }^{1}$ Materials Engineering, E.I.I., Universidad de Valladolid, 47011 Valladolid, Spain

${ }^{2}$ UVASENS, E.I.I., Universidad de Valladolid, 47011 Valladolid, Spain

* Corresponding author. Prof. Garcia-Cabezon, Tel.: +34 983423389.

E-mail address: crigar@eii.uva.es (C. Garcia-Cabezon).

\begin{abstract}
A strategy for the corrosion protection of porous materials using conductive polymers and nanocomposites of polymers and nanoparticle is presented. Several conductive polymers, various dopants and different electropolymerization conditions are studied to select the films with the highest corrosion resistance on porous and nonporous materials. It is found that nanocomposite films prepared from two different methods i.e., the co-generation of $\mathrm{Au}$ nanoparticles and the dispersion of $\mathrm{TiO}_{2}$ nanoparticles inside the selected polymer coating give rise to an excellent corrosion resistance. Coated porous samples have the most noble corrosion potentials, the lowest stable passive current densities and the highest polarization resistances.
\end{abstract}

Keywords: Porous materials, Stainless steel; Corrosion Behavior; Nano particles, Conductive polymer. 


\section{INTRODUCTION}

The use of protective coatings is the most common strategy to improve the corrosion resistance of metallic materials. In recent years, conductive polymers have been of great interest for their potential applications, not only in corrosion protection $[1,2]$ but also in biomedicine [3] sensors [4,5], rechargeable batteries, catalysis and microbial fuel cells [6,7], among many others. Polypyrrol (PPy), polyaniline (PA) and poly (3,4-ethylene-dioxyethiophene (PEDOT)) are three of the most common conductive polymers used for the corrosion protection of active metals, such as copper [8], aluminium [9], iron and steel [10] or nickel and titanium [11], as well as stainless steels $[12,13]$. From these studies, it is known that the formation and effectiveness of these films depends largely on how they are applied and the conditions of the corrosion experiments. Therefore, depending on the polymerization conditions (concentration, current, potential) on the composition of the electrolyte (dopant) and on the nature of the metallic substrate, an excellent protection capacity can be obtained or, on the other hand, a disastrous corrosion attack can be caused.

Taking into account the fact that the effectiveness of polymers as a barrier and/or inhibiting effect is a function of the degree of attachment to the metal surface, the adhesion of the polymer to the substrate is one of the most critical parameters; the loss of adhesion causes delamination, which is the main cause of the corrosive attack on the substrate $[11,14]$. One strategy to solve this problem is the use of porous substrates, since their porosity could improve the adhesion of the film. Most of the works referred to have been carried out on non-porous substrates. In the present work, porous substrates will be used, with which it is expected to improve the adhesion of the polymer film. 
In recent years, noble metal noble nanoparticles have attracted much interest due to their excellent and different properties from bulk materials. The high ratio of atoms on the surface to atoms on the bulk, in addition to the quantum effects, has promoted their use in such technological fields as spectroscopies, biomedicine, catalysis, etc. [15]. Gold nanoparticles (AuNPs) are well-known for their antibacterial, antifungal, optical, electronic or catalytic properties, among others $[16,17]$. Nanocomposites of noble metal nanoparticles in an organic matrix are highly promising materials that combine the molecular ordering of organic materials such as conductive polymers and the quantumconfined properties of metal NPs. The properties of these hybrid materials depends not only on the nature of the NPs and the conductive polymer, but also on the size, shape and distribution of the NPs in the organic matrix $[18,19]$. There are some applications of this kind of nanocomposite to improve the corrosion resistance of biomaterials such as titanium alloys [20] or stainless steels [21] in physiological solutions. Once again, there are no studies on porous metallic substrates.

In addition, the electronic, optical and electrochemical properties of conducting polymers could be improved by combining them with metal oxide nanoparticles. Hosseini et al. [22] have proven that the dispersion of $\mathrm{TiO}_{2}, \mathrm{Mn}_{2} \mathrm{O}, \mathrm{ZnO}$ NPs within a PPy matrix on aluminium electrode alloys improves the corrosion resistance in aggressive environments, especially for $\mathrm{TiO}_{2} \mathrm{NPs}$. This enhancement of the performance of these coatings has been associated with the increase in barrier properties and the increase in the lifetime of organic coatings [23,24]. Kumar et al. [25-27] have demonstrated that the incorporation of metallic oxide $\mathrm{NPs}$, such as $\mathrm{Nb}_{2} \mathrm{O}_{5}, \mathrm{ZrO}_{2}$ or $\mathrm{TiO}_{2}$, to the electropolymerization of PPy can be successfully used to produce bioactive nanocomposite coatings over stainless steels for orthopaedic implants. On the other hand, these nanocomposites of metallic oxides and conductive polymers deposited on 
metallic substrates are very interesting as electrodes for fuel cells. Stainless steels are selected as anode electrodes of microbial fuel cells due to their low cost and good mechanical properties; however, their corrosion resistance needs to be improved [28, 29]. The electrodeposition of $\mathrm{MnO}_{2}$ on PPy coated stainless steels has made it possible to enhance electrochemical activities in microbial fuel cells [30]. Therefore, porous stainless steels could be a good alternative as electrodes for fuel cells due their intrinsic porosity.

AISI 316L SS is one of the austenitic stainless steels most widely used in the manufacturing of components in the automotive, food, chemical, energy and medical industries; it is known for exhibiting a good combination of corrosion, oxidation and mechanical properties in highly aggressive mediums [31,32]. Powder metallurgy (P/M) is a feasible and economic processing technique of porous austenitic stainless steels; it provides net or near-net shape, good mechanical properties, high surface finish and dimensional precision with porosity control [33-35]. It is known that the corrosion resistance of porous stainless steels is significantly lower than that of either cast or wrought stainless steel due to the inherently residual porosity. The high surface area exposed to the environment and the formation of oxygen concentration cells within the pores increase the susceptibility to corrosion [36]. This is particularly relevant in acid environments with chlorides [37], although this has also been confirmed in other environments such as biological solutions [38]. Therefore, there is a great need to improve the corrosion resistance of these porous materials to expand their industrial applications.

As mentioned above, fuel cells could be one of the possible applications of these compounds. One of the limitations of this technology is that the energy generation is $\underline{\text { still too low and is mainly related to the electrode materials [28-30]. The ideal electrode }}$ 
should have conductivity, large surface area, good mechanical strength, low cost and high corrosion resistance in high aggressive environments. The nanocomposites of PPy and NPs coated porous SS could be a good candidate since the electrode surface area is one key parameter. The higher area provides larger active surface and reduce the charge transfer resistance. For simulated high aggressive environment, acid solution with chlorides has been used on corrosion testing.

The main objective of this work is to study the effect that coatings of conductive polymers, with and without nanoparticles, have on porous materials from the point of view of corrosion resistance. For this purpose, the conductive polymer, the dopant and the electropolymerization conditions that achieve the best corrosion resistance will be selected. Then the effect of the dispersion of metallic AuNPs and metallic oxide nanoparticles, such as $\mathrm{TiO}_{2}$, in the selected conductive polymer is studied. The coating films are characterized by scanning electron microscope (SEM) and transmission electron microscopy (TEM). The protective effect of the coating films is investigated by open circuit, potentiodynamic techniques and electrochemical impedance spectroscopy in an acid environment with chlorides. Porous steel 316L, obtained by powder metallurgy using two different sintering atmospheres, has been selected as the porous substrates. Wrought $316 \mathrm{~L}$ stainless steel is used as a reference material to analyse the effect of the porosity and sintering conditions of the porous samples.

\section{EXPERIMENTAL}

\section{Materials and methods}

\subsection{Chemicals}

Pyrrol, aniline, 3,4-ethylenedioxythiophene, poly (styrene sulfonate), dodecylbenzene sulphonate acid sodium salt (DBSA), lithium perchlorate, oxalic acid, 
sulphuric acid, sodium chloride, and tetrachloroauric acid were all purchased from Sigma-Aldrich. Solvents were of reagent grade and used as supplied. Solutions were prepared by dissolving substances in deionized water (resistivity $18.2 \mathrm{M} \Omega \cdot \mathrm{cm}-1$ ) obtained from a Milli-Q system (Millipore, Billerica, MA, USA).

Gold nanoparticle (AuNP) colloids were synthesized at the same time as the polypyrrol film is formed, using the "cogeneration method", by mixing a solution containing chloroauric acid $10^{-3} \mathrm{~mol} / \mathrm{L}$ and a solution containing pyrrol-DBSA. In this method, and according to the oxidation potentials of pyrrole $\left(0.7 \mathrm{~V}_{\mathrm{Ag} / \mathrm{AgCl}}\right)$ and the reduction potential of $\mathrm{AuCl}^{-4}\left(1 \mathrm{~V}_{\mathrm{Ag} / \mathrm{AgCl}}\right)$, the AuNPs where generated in situ and inserted in the polymeric film during the electrochemical growth. Titanium (IV) oxide nanoparticles $\left(\mathrm{TiO}_{2} \mathrm{NPs}\right)$ were purchased from Sigma-Aldrich.

\subsection{Materials}

The porous samples were obtained by PM using an atomized austenitic AISI 316L SS powder (HÖGANÄS, Belgium). The characteristics of the powder were: chemical composition $(0.021 \% \mathrm{C}, 0.2 \% \mathrm{Mn}, 0.87 \% \mathrm{Si}, 13.55 \% \mathrm{Ni}, 16.1 \% \mathrm{Cr}, 2.24 \%$, $0.02 \% \mathrm{Cu}$ ), apparent density $2.87 \mathrm{~g} / \mathrm{cm}^{3}$, flow rate $25 \mathrm{~s} / 50 \mathrm{~g}$ and nominal particle size $<150 \mu \mathrm{m}$. Wrought austenitic 316L SS (Acerinox, Spain), with chemical composition (0.030\% C, $1.26 \% \mathrm{Mn}, 0.34 \% \mathrm{Si}, 10.85 \% \mathrm{Ni}, 17.3 \% \mathrm{Cr}, 2 \% \mathrm{Mo}, 0.33 \% \mathrm{Cu})$, was used on a comparative basis. Although the compositions were not exact, the differences were not significant.

Porous samples with cylinder morphology of $12 \mathrm{~mm}$ in diameter and $6 \mathrm{~mm}$ in height were obtained using uniaxial compaction at $750 \mathrm{MPa}$ for $300 \mathrm{~s}$ with a floating die and zinc stearate as die lubricant. Two sintering atmospheres were used. Some compacted samples were sintered in a $(95 \%-5 \%) \mathrm{N}_{2}-\mathrm{H}_{2}$ atmosphere and others were sintered at low vacuum $(11 \mathrm{~Pa})$ to minimize chromium losses. Both were heated to 
$1250^{\circ} \mathrm{C}$ for 1 hour at $5^{\circ} \mathrm{C} /$ minute. The samples sintered in nitrogen were cooled in water to avoid the precipitation of nitrides [39], these samples are referred to as nitrogen $(\mathrm{N})$; while those sintered in a vacuum were cooled in the furnace to avoid oxidation problems and are referred to as vacuum (V). Wrought SS is referred to as (W).

\subsection{Deposition of conducting polymers coatings}

To obtain the coatings, the electropolymerization technique was used. It was carried out on an EG\&G Parstat 273A potentiostat/galvanostat at room temperature, with the classic three-electrode configuration. A platinum plate was used as counter electrode, the $\mathrm{Ag} / \mathrm{AgCl}$ electrode in a $3 \mathrm{~mol} / \mathrm{L} \mathrm{KCl}$ solution as reference electrode and the stainless steel samples with final polishing, with 0.3 micron alumina and cleaning in an ultrasonic bath, as working electrode.

Some PPy and PA films were obtained by electropolymerization from a solution containing $0.1 \mathrm{~mol} / \mathrm{L}$ pyrrol/anilina and $0.25 \mathrm{~mol} / \mathrm{L}$ oxalic acid as dopant. Other PPy films were obtained using the same amount of monomer and $0.05 \mathrm{~mol} / \mathrm{L}$ DBSA as dopant.-. The PEDOT/PSS films were obtained from a solution containing $0.01 \mathrm{~mol} / \mathrm{L}$ EDOT and $0.1 \mathrm{~mol} / \mathrm{L}$ of PSS. $\mathrm{ETw}$ - different electrochemical techniques: chronopotentiometry $(\mathrm{CP})$ at a current density of $0.02 \mathrm{~mA} / \mathrm{mm}^{2} \mathrm{~s}$ and chrono-amperometry (CA) at a potential of $0.8 \mathrm{~V}_{\mathrm{Ag} / \mathrm{AgCl}}$, in both cases for $800 \mathrm{~s}$. The films were deposited on the forged PM and SS surfaces.

\subsection{Deposition of nanocomposite coatings}

PPy-AuNp films doped with DBSA were deposited using a solution containing the monomer, the dopant and chloroauric acid as the precursor of the gold nanoparticles. PPy- $\mathrm{TiO}_{2} \mathrm{NPs}$ were prepared following a similar method by mixing the 
monomer/dopant solution with the corresponding metal oxide nanoparticle $(0.2 \mathrm{mg} / \mathrm{ml})$ after $30 \mathrm{~min}$ sonication. Chrono-potentiometry (CP) at a current density of 0.02 $\mathrm{mA} / \mathrm{mm}^{2}$ during $800 \mathrm{~s}$ was applied for electrodeposition nanocomposite films over PM and wrought SS. Once prepared, the polymeric films were extracted from the generation solution and washed thoroughly with water.

\subsection{Characterization}

Immersion of the Archimedes method was used to determine the density of the sintered samples and image analysis to determine the degree of porosity. The microstructural characterization of the surface of the substrates and coatings was carried out with the SEM-FEI (QUANTA 200F) equipment.

The peel test (ASTM D 3359), method A [40], was used to determine the adhesion of the coatings in order to select the best doping and electropolymerization conditions. Two cuts were made in the film, intersecting near its centre, with a small angle $\left(30^{\circ}\right.$ and $\left.45^{\circ}\right)$, then an adhesive tape was pressed to the striped sample for $60 \mathrm{~s}$ and removed and the X-cut area was checked to remove the coating from the substrate.

\subsection{Electrochemical corrosion measurements}

Electrochemical corrosion measurements were carried out in acid solution with chloride containing $0.5 \mathrm{M} \mathrm{NaCl}+0.5 \mathrm{M} \mathrm{H}_{2} \mathrm{SO}_{4}$ at $30^{\circ} \mathrm{C} \pm 1$ using a Saturated Calomel Electrode (SCE) as the reference electrode. The electrochemical methods included open circuit potential (OCP) during 4000s and potentiodynamic anodic polarization measurements.

ASTM standard G-5 [41] was applied to the anodic polarization curves. The test conditions were: initial potential $=350 \mathrm{mV}_{\mathrm{SCE}}$ below $\mathrm{V}_{\mathrm{OC}}$, final potential $=1200$ 
$\mathrm{mV}_{\text {SCE}}$, sweep speed $=50 \mathrm{mV} / \mathrm{min}$, temperature $=30^{\circ} \mathrm{C}$. The surface preparation of the metal samples was carried out with 1 micron diamond paste. Deaeration with nitrogen and agitation was maintained throughout the test. After the test, the samples were examined by optical microscopy. Tafel's analysis was used to determine corrosion rate, corrosion potentials and corrosion current densities. All tests were performed in triplicate for each sample with coefficients of variation between these tests of less than $5 \%$.

Electrochemical Impedance Spectroscopy (EIS) measurements were conducted using impedance analyser Solartron SI 1260 combined with EG\&G potentiostat 273A. Impedance spectra were acquired in acid chloride solution with a frequency range from $\underline{1 \mathrm{MHz} \text { to } 0.01 \mathrm{~Hz} \text { and a signal amplitude of } 10 \mathrm{mV} \text { at OCP after a stabilization step at }}$ open circuit during 1800 s. Impedance data were managed with Zview software and fitted to equivalent circuits. Tests were repeated three times.

\section{RESULTS AND DISCUSSION}

\subsection{Electropoylymerization of conductive polymer coatings.}

The electropolymerization of the three monomers (aniline, pyrrol or edot) on every sample was generated under CP or CA conditions; always resulting in the formation of an electroactive polymer film. Fig. 1a shows the potential vs. time curves registered during the electrodeposition of the PPy/DBSA films using a $\mathrm{CP}$ process. For all the samples, a strong initial drop in potential was observed, related to the charge of the double layer capacitance that produces a nucleation process on the electrode surface. This was followed by a stabilization and growth stage of the layer in which the potential is stable [42]. The behaviour was the same for all the monomers, although PA showed 
the lowest stable potential value and PEDOT the highest. The adhesion of the coating was satisfactory in all samples, since the film was not removed at all after the peeling test.

The CA technique was used to prepare other coatings. Fig. 1b shows the density current vs. time for the electrodeposition of the PPy/DBSA film, as an example. As expected, in all cases, an initial sharp decrease in current density was observed. This can be related to an induction step where the monomer oxidation was controlled by diffusion, followed by the nucleation and growth of the polymer film on the electrode surface which caused the current to increase rapidly over time. Finally, the current density was stabilized, indicating the progressive growth of the film [43]. For all conductive polymer electrodepositions by CA, the wrought samples showed the lowest current densities, indicating lower electrical charges than for porous samples. In addition, for wrought samples, the detachment of the coating was observed during normal handling. Additionally, the results of the adherence test indicated the removal of most of the $X$ area under the tape in the case of the wrought samples. Additional studies were conducted using potentials other than $0.8 \mathrm{~V}$ such as $0.6 \mathrm{~V}$ and $1 \mathrm{~V}$. Figure $1 \mathrm{c}$ is an example for PEDOT/PSS deposition on the wrought sample. For CA at higher potential thicker layers were obtained but still detached; with lower potential no uniform deposition was achieved. In view of this poor performance, the CA electrodeposited technique was discarded and CP was selected for electrodeposited coating submitted to corrosion testing.

\subsection{Corrosion protection abilities of conductive polymer coatings.}

The corrosion resistance of uncoated and coated samples were evaluated, in $0.5 \mathrm{M}$ $\mathrm{NaCl}+0.5 \mathrm{M} \mathrm{H}_{2} \mathrm{SO}_{4}$, by means of open circuit and potentiodynamic tests. Firstly, the 
effect of the dopants on the PPy films was analysed; secondly, the effect of the type of conductive polymer was studied; and thirdly, the effect of the substrate was investigated. From these results, the coated film with the best corrosion protection capabilities was selected. The best one was subsequently modified with nanoparticles.

It is known that the doping process in conductive polymers is the key to explaining their conductivity [22]. Doping agents can be separated into two categories according to their molecular size: small and large. Since both the conductivity and the structural properties of the polymer depend on the size, it is very likely that this will also affect the ability to protect against corrosion. In the case of PPy films, two different dopants: Oxalic acid and DBSA as small and large dopants, respectively, were used.

Fig. 2a shows the open circuit test of the two forms of Oxalic or DBSA doped PPy, as well as the uncoated material. Initially, both the PPy films displaced the potential of the SS to the passive state, as compared to the uncoated SS. In addition, the coated samples showed a higher potential than the uncoated samples throughout the test; the uncoated samples remained in the active state over time. However, the potential achieved by PPy/DBSA is initially higher and much more stable than that of PPy/Oxalic, although the final potentials were very similar. The ennoblement of the potential with the coating was observed for both sintered and wrought samples; although the latter had a slightly more noble potential than the porous samples. The anodic polarization curves, Fig $2 \mathrm{~b}$, confirmed the beneficial effect of the deposition of the PPy coatings, as the curves were shifted to the right and upwards, indicating that the potentials were more noble and the current densities lower. These changes were greater for PPy/DBSA. Generally, the $\mathrm{E}_{\text {corr }}$ is smaller than the corresponding $\mathrm{E}_{\mathrm{ocp}}$, which could be due to the depassivation process on the surface during cathodic scanning. 
Nevertheless, open circuit and polarization tests agree in pointing to the beneficial effect of the coatings.

The well-known relation between the protective capacity of PPy film and the doping/undoping process should be considered to explain these results. Metal oxidation (anodic reaction) is the driving force behind the doping process (cathodic reaction) [44]. Large doping agents, such as DBSA, are more integrated into the polymer and do not migrate as easily over time, giving the polymer greater electrochemical stability. Small dopants, such as oxalate ion, are easily expelled in the cathodic reaction, favouring anion exchange with chloride anions. On the other hand, DBSA is a surfactant and is capable of creating micelles incorporated into the polymer matrix. The negatively charged surface of these micelles could attract cations and repel anions, such as chlorides, and then corrosion resistance would increase. This behaviour has also been observed for other metallic substrates, such as copper or carbon steel $[45,46]$. In order to select the most resistant polymer coating in a $0.5 \mathrm{M} \mathrm{NaCl}+0.5 \mathrm{M} \mathrm{H}_{2} \mathrm{SO}_{4}$ solution, a comparative study of the protective capability of three different conductive polymers, PPy/DBSA, PA/Oxalic and PEDOT/PSS, were carried out. It was observed from Fig 2c that these three coatings caused a shift in the corrosion potential to a more noble value. Furthermore, both anodic and cathodic branches moved to lower current densities. The anodic branch implies dissolution, passivation and passive film breakdown. The lowest passive current density and the more extended passive region are an indication of higher corrosion resistance; therefore, PPy/DBSA showed the best protection ability.

The parameters such as corrosion potential $\left(\mathrm{E}_{\mathrm{corr}}\right)$, corrosion current density $\left(\mathrm{i}_{\text {corr }}\right)$, Tafel constants $\left(\beta_{\mathrm{a}}\right.$ and $\left.\beta_{\mathrm{c}}\right)$, polarization resistance $\left(\mathrm{R}_{\mathrm{p}}\right)$ and protection efficiency $(\mathrm{PE} \%)$ are listed in Table 1. The polarization resistance and the protection efficiency were obtained by using the following expressions: 


$$
\begin{gathered}
R_{P}=\frac{\beta_{a} \times \beta_{c}}{2.303\left(\beta_{a}+\beta_{c}\right) \times i_{\text {CORR }}} \\
P E \%=\left(\frac{R_{\text {Coated }}-R_{\text {Uncoated }}}{R_{\text {coated }}} \times 100\right)
\end{gathered}
$$

Table 1 shows that all polymer coatings caused a remarkable potential shift in $\mathrm{E}_{\text {corr }}$ toward more noble potentials. The three coatings lead to significant decreases in $\mathrm{i}_{\text {corr }}$ and significant increases in $R_{p}$, resulting in significant protection efficiency values. For all samples, the highest PE\% (73-95.5) was found for PPy/DBSA.

Fig $2 \mathrm{~d}$ shows the potentiodynamic polarization curves of the uncoated and PPy/DBSA coating samples for the different sintering conditions, as well as for the wrought material. In the case of porous samples, it is impossible to calculate the actual current density, since the surface of the pores wetted by the electrolyte is unknown, so the current density is overestimated [39]. The porosity and sintering density of the nitrogen sintered sample were around $11 \%$ and $7.2 \mathrm{~g} / \mathrm{cm}^{3}$; while, for the vacuum sintered sample, the values were around $12 \%$ and $6.9 \mathrm{~g} / \mathrm{cm}^{3}$, respectively; so, on a comparative basis, the influence of porosity will always be similar. The wrought sample was free of pores, so the real exposed area was lower than that for the sintered samples and the anodic curve shifted to a lower current density. It is indicative of the poor corrosion resistance of the uncovered sintered samples.

The PPy/DBSA coating modifies the polarization curves, but in a very different way for porous and non-porous materials. The changes were more significant for PM samples, since the $\mathrm{E}_{\text {corr }}$ potential shifted to nobler values, the passive current density decreased and the breakdown potential increased. Furthermore, the V-PPy/DBSA sample showed the lowest current density, while the N-PPy/DBSA samples showed the 
most stable and larger passive range. The beneficial effect of the PPy/DBSA coating on the wrought sample was less intense, but so were the potential increases and the current density decreases. The effect of the substrate is similar to the other two polymers; figure 2e corresponds to the PA/Oxalic coatings. It can be seen the improvement for PM samples although the W-PA/Oxalic showed nobler potential and lower current density $\underline{\text { than porous substrates. }}$

According to the literature, the corrosion protection mechanisms proposed to explain the role of conducting polymers in metal substrates $[22,47]$ are multiple. The barrier effect, the anodic protection and the displacement of the electrochemical interface are the most common. The results demonstrate that the coatings are an effective barrier to the diffusion of chloride ions. Also, the polymer applied in its conductive state can act as an oxidizer at the polymer/metal interface, or even keep the metal in the passive domain in small defective areas. The anodic protection provided by the coatings would explain the increased corrosion potential and the formation of a more stable and lower current density passive layer. Moreover, the inhibition effect of dopant ions should be important; considering their large size during the reduction process, the DBSA anions remain trapped in the polymer and could incorporate anion micelles, thus providing a more effective barrier against the penetration of chloride anions.

The quantitative effect of the metallic substrate on the corrosion resistance of PPy/DBSA coating was analysed by Tafel analysis, Table 1. As expected, the effective protection was higher for sintered than for wrought samples and, as a consequence of this, the negative effect of porosity disappeared. The lowest values of passive current density and the largest passive potential range were observed in N-PPy/DBSA. To 
explain these results, the microstructure of coated and uncoated samples must necessarily be analysed.

SEM micrographic images of PPy coating samples for sintered and wrought samples are shown in Fig. 3. For the sintered samples, Fig 3a, the coating showed a homogeneous, globular, compact and fine-grained cauliflower structure. PPy coating on the wrought sample, Fig 3b, also had a compact and globular distribution, but a coarse grain size and it showed some heterogeneities. Some smooth areas interconnected with globular areas with pores inside can be seen in Fig 3c. The more homogeneous and fine-grained microstructure for the sintered samples could be related to a higher adhesion of the coating due to the presence of pores. In a previous work [48], the authors explained the high corrosion resistance observed in porous coated samples in biological media by the improvement in the morphological properties. Concerning the influence of the sintering atmosphere, both samples showed a precipitate-free austenitic microstructure, Figs $3 \mathrm{~d}$ and 3e. However, the higher content of nitrogen in the solid solution of the austenite for the nitrogen sintered sample could lead to the formation of a more corrosion resistant passive layer; thus justifying the better corrosion behaviour of the nitrogen sintered sample, also in the presence of the coating.

\subsection{Electropoylymerization of nanocomposite coatings}

Figs $4 \mathrm{a}$ and $4 \mathrm{~b}$ show the $\mathrm{CP}$ curves for PPy/DBSA-AuNPs and PPy/DBSA$\mathrm{TiO}_{2} \mathrm{NPs}$ nanocomposites, respectively, in a mixture of pyrrol, DBSA and trichloroauric acid or pyrrol, DBSA and $\mathrm{TiO}_{2} \mathrm{NPs}$ on sintered and wrought samples. All the curves were similar in shape to each other and similar to those obtained for the PPy coating. However, some differences were observed. For PPy/DBSA-AuNPs nanocomposites, the highest nucleation rate (faster electrode potential variation) was observed when PPy was 
polymerized in the absence of trichloroauric acid precursor. At the same time, the final potential (at which the monomer was oxidized) was higher for PPy/DBSA-AuNPs films. According to these results, it can be assumed that the formation of AuNPs at the same time as the electropolymerization affects the nucleation of PPy, making the oxidation of the monomers more difficult. On the contrary, in the case of PPy/DBSA$\mathrm{TiO}_{2}$ nanocomposites, the presence of already formed nanoparticles in the solution mixture increased the nucleation rate and decreased the final potential. Therefore, the final potential attained, when polymerization was carried out in the presence of previously formed nanoparticles (trapping), was lower than the potential obtained when nanoparticles were generated in situ (cogeneration). This result seems to confirm that nanoparticles affect the nucleation process. Only a small difference was found in the final potential attained by nanocomposites deposited on sintered and wrought SS, although the final potential was slightly lower for the latter substrate.

All the nanocomposites coatings exhibited no failed regions after tape adhesion test, which indicates good adhesive resistance on SS surface.

The microscopic structure of the PPy/DBSA-AuNP nanocomposites analysed by SEM confirmed the incorporation of the AuNPs into the PPy films over sintered and wrought SS samples, Fig. 5. The PPy/DBSA-AuNPs films obtained on sintered substrates showed a uniform globular morphology with AuNPs uniformly dispersed in the polymer matrix, Fig. 5a. The morphology of PPy/DBSA-AuNPs films on wrought samples was a cauliflower type structure with a higher degree of roughness and higher grain size than observed in covered sintered samples, Fig 5b. This different morphology had already been observed for PPy films. For both substrates, the formation of AuNPs in a PPy matrix created a finer and less porous morphology coating than a PPy one 
without nanoparticles. In all cases, the medium size of AuNPs was around 30-40 nm, Fig $5 \mathrm{c}$.

As can be seen in Fig $5 \mathrm{~d}$, the presence of the $\mathrm{TiO}_{2}$ was confirmed by SEM micrographs. The incorporation of oxide nanoparticles strongly modified the PPy films. The PPy/DBSA-TiO 2 nanocomposites presented a smooth and granular structure, where the typical cauliflower morphology was not visible. Therefore, the presence of oxide nanoparticles interfered with the PPy electropolymerization, leading to an increased compactness of the coating. The structures of nanocomposite films deposited onto sintered or wrought SS were almost identical. It has already been reported for others oxide nanoparticles [33-35, 49], concluding that the interaction between the metal oxide and the polymer chains during electrodeposition leads to a fine, spherical grain structure in the PPy matrix. The structures of nanocomposite films deposited onto sintered or wrought substrates were almost identical. From Fig 5 d, the presence of aggregates can be seen in addition to individual nanoparticles dispersed in the matrix. The TEM image of one of these aggregates is shown in Fig $5 \mathrm{e}$, the average size of the $\mathrm{TiO}_{2}$ nanoparticles being around $10-15 \mathrm{~nm}$.

The anodic polarization curves for both uncoated samples and those coated with PPy/DBSA, PPy/DBSA-AuNPs and PPy/DBSA-TiO ${ }_{2} \mathrm{NPs}$, in substrates sintered in nitrogen atmosphere, are shown in Fig. 6a. The morphology of the curves corresponding to the coated samples is similar in all of them, but very different from that observed in the bare substrate. A more stable, passive layer and a more noble breakdown potential was observed for coated samples. The incorporation of nanoparticles shifted the polarization curve to lower current densities and a more noble potential was observed, an indication of an ulterior improvement in corrosion resistance with respect to simple 
PPy coating. A similar displacement was observed for substrates sintered in a vacuum and for the wrought substrate.

In order to evaluate the effect of the porosity of the substrate, Fig. $6 \mathrm{~b}$ and Fig. $6 \mathrm{c}$ show the anodic behaviour for PPy/DBSA-AuNPs and PPy/DBSA-TiO ${ }_{2} \mathrm{NPs}$, respectively, for samples sintered in nitrogen atmosphere, in a vacuum and the nonporous wrought substrate. In the case of nanocomposite coatings, the influence of the substrate was clearly lower and all the samples had a similar anodic behaviour. The sintered samples had similar or even lower current densities than the wrought sample. The differences were even more limited for the PPy/DBSA-TiO ${ }_{2}$ nanocomposites. This could be explained by considering the remarkable changes in the microstructures of every coating in function of the substrate.

In addition, for all substrates, a change in the open circuit potential towards more noble values was registered when nanocomposite coatings were applied. This was in good agreement with the anodic polarization curves. This suggests the formation of a more protective passive layer because the nanocomposites act as electronic/chemical and physical barriers to prevent diffusion of the oxygen and chloride anions [50].

The electrochemical parameters calculated from the polarization data are collected in Table 2. According to the Tafel analysis, the incorporation of inorganic materials at the nanoscale into the organic coating greatly improves desirable properties in organic films, such as the barrier effect, layer adhesion and layer cohesion. It was found that the addition of AuNPs increased the $\mathrm{R}_{\mathrm{p}}$ and $\mathrm{PE} \%$ for all samples, but the increase was even more significant in the case of $\mathrm{TiO}_{2} \mathrm{NPs}$ addition.

The inhibition efficiency values obtained for polarization measurements revealed that the electrochemical nanocomposite coatings have greater protection efficiency than pure PPy/DBSA, especially for wrought SS. The incorporation of 
nanoparticles achieved more homogeneous, smoother and less porous coatings. The enhanced compactness of the nanocomposites allowed a significant improvement in corrosion resistance by preventing the electrolyte from reaching the substrate. This is in accordance with the SEM microstructure, since a finer and more compact grain and homogenous microstructure is obtained when polymer electrodeposition and AuNP formation occur at the same time (cogeneration method). In the literature, the improvement in corrosion resistance associated to AuNPs has been attributed to the improvement in barrier effects due to a more compact coating [28,29]. On the other hand, the increased conductivity of the polymer, along with the incorporation of AuNPs, could also influence the protective capability.

The maximum inhibition efficiency $(98.32 \%)$ was obtained for PPy/DBSA$\mathrm{TiO}_{2} \mathrm{NPs}$ nanocomposites. This improvement could be related to the change in morphology of the PPy matrix from cauliflower-like to the smooth and globular particle shape. Similar behaviour has been referenced for wrought $316 \mathrm{~L}$ SS with the incorporation of oxide nanoparticles such as $\mathrm{ZrO}_{2}, \mathrm{TiO}_{2}[34,36]$ or $\mathrm{MnO}_{2}$ [38] in PPy coatings on biological media.

Impedance measurements confirmed the OCP and anodic potentiodynamic results. EIS data were recorded after immersion non-coated and coated SS in aggressive solution for 800 s to determine the effectiveness of PPy/DBSA, PPy/DBSA-AuNPs and $\underline{\text { PPy/DBSA-TiO }} 2 \underline{2}_{2}$ coatings but also to providing information of the corrosion mechanisms. Fig. 7a, 7b and 7c show the Nyquist and Bode plots of un-coated PM sintered in nitrogen atmosphere and coated PPy/DBSA in presence and in absent of nanoparticles.

The Nyquist diagram revealed two depressed capacitive loopss, one at high frequencies and another at low frequencies. These semicircles increased radius for 
coated samples; bearing in mind that the larger the radius of the semicircle, the greater the resistance to polarization of the material, it can be said that the corrosion resistance increased with the PPy coatings and specially in the presence of nanoparticles. The impedance modulus was larger than one order of magnitude for the PPy/DBSA sample $\underline{\text { than the uncoated sample and larger than one and a half order for PPY/DBSA-TiO } 2} \underline{2}$ NPS $\underline{\text { nanocomposite which indicates its better corrosion behaviour. }}$

For the interpretation of the impedance spectra, an appropriate equivalent electric circuit should be chosen. The depression of the circles indicates non-ideal capacitive behavior and therefore a constant phase CPE element is introduced into the circuit to give a more accurate fit. Fig. 7d shows the equivalent electric circuit proposed, Figs $7 \mathrm{a}, 7 \mathrm{~b}$ and $7 \mathrm{c}$ collect the results of the fitting and the parameters of the fitting are presented in Table 3. Chi-square values, $\chi^{2}$, were used to evaluate the fittings quality, it was of a magnitude to the order of $10^{-3}-10^{-4}$. In the proposed model for non-coated sample, $\mathrm{CPE}_{1}$ is the first time constant and it is represented by capacitance of the passive film in pore-free areas, and $\mathrm{R}_{1}$ is the resistance of porous oxide passive layer impregnated with electrolyte. The electrolyte can penetrate through the pores of the passive layer. These defects lead to the appearance of double-layer capacitance $\left(\mathrm{CPE}_{2}\right)$ and the charge-transfer resistance $\left(\mathrm{R}_{2}\right)$, this second time constant related to the dissolution of the metal due to the formation of a non-protective passive layer. For coated samples, $\mathrm{CPE}_{1}$ and $\mathrm{R}_{1}$ relate to the high frequencies time constant associated to the porous coating. $\mathrm{C}_{2}$ and $\mathrm{R}_{2}$ can be related with the double-layer capacitance and the charge-transfer resistance through porous coating, respectively.

Table 3 show the important increased $\mathrm{f}_{1} \underline{1}_{1}$ and $\mathrm{R}_{2}$ with the coatings. The sum of

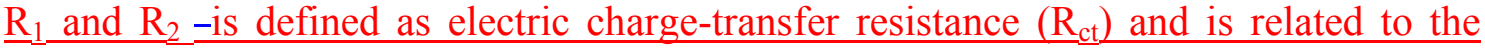
corrosion resistance; this clearly increased for coated samples. The higher value of $\mathrm{R}_{\underline{c t}}$ 
of PPy/DBSA sample is attributed to the effective barrier behavior of the polymer coating. Furthermore, the value of $\mathrm{R}_{\mathrm{ct}}$ increases specially in presence of nanoparticles. The nanoparticles decrease the porosity of PPy and it inhibits the ions and water penetration into the coating and subsequent electrochemical reactions at the coating/metal interface, leading to improved barrier performance of the nanocomposite coating.

In good agreement with the OCP and polarization measurements, the maximum $\underline{\mathrm{R}}_{\mathrm{ct}}$ values was obtained for-Ppy/DBSA-TiO 2 . The synergist effect between PPy and $\mathrm{TiO}_{2}$ has been reported for other substrates as copper by Beikmohammadi et al. [51] or aluminium by Hosseini et al. [52]. It is shown that PPy being p-type presents a large barrier for electron transport while $\mathrm{TiO}_{2}$ being n-type, gives hindrance to hole transport across the interface. In addition, the different position of the valence bands and the wide energy range make load transport between the two semiconductors difficult. The same has been observed for $\mathrm{Al}_{2} \underline{0}_{3}$ nanoparticles (n-type) and PPy (p-type) on steel [53]. The good corrosion behaviour observed for $\mathrm{PPy}^{-} \mathrm{TiO}_{2}$ nanocomposites has been attributed to the combination of several factors [51-53]. One of this is the formation of a passive layer in which the conductive polymer acts as a physical, electronic and chemical barrier to diffusion of oxygen and aggressive ions and the nanoparticles improve this barrier effect by decreasing the porosity. Other effect is the high specific surface area of nanoparticles that increasing the surface area available for releasinge of dopant on $\underline{\text { nanocomposite. Finally, the hetero-junction formation between PPy (n-type) and } \mathrm{TiO}_{2}}$ (p-type) promotes a potential barrier for charge transport that leads to much better performance for $\mathrm{PPy}-\mathrm{TiO}_{2}$ nanocomposites. In this work, it has been proven that this also happens in a strong corrosive medium for porous SS; achieving protection capabilities similar to or even higher than those observed in bare wrought SS. 
Therefore, in this work, it has been demonstrated that there is a synergistic effect between nanoparticles and conductive polymer coatings, leading to a very important improvement in the corrosion protection. This effect occurs in different ways, such as preventing the access of corrosive ions to the substrate thanks to the nanometric size of the additives. In addition, the changes induced in the conductivity of the polymer and the increase in the active surface of the polymer are both relevant factors. All these elements lead to a much better performance than the uncoated component systems analysed above.

\section{CONCLUSIONS}

Porous materials have multiple potential applications; however, their use is currently limited by their poor corrosion resistance due to their intrinsic porosity. Therefore, it is advisable to search for possible solutions to this issue.

The electrochemical behaviour of coated and uncoated porous and non-porous materials is investigated in highly aggressive acid chloride solutions. The OCP evolution results and the anodic polarization measurements show that porosity greatly increases their corrosion susceptibility.

In a first experiment, conductive polymer coatings are used to solve this problem. It is shown that the effectiveness of the coating depends largely on the type of polymer, the dopant used, the polymerization conditions and the substrate. The PPy films doped with DBSA, using the CP electrodeposition method, is successfully employed to improve the corrosion resistance. The PPy coating stabilizes the OCP and modifies the polarization curves, but its effect is different for each substrate depending on the surface morphology of the coating. The pores play a beneficial role in the 
adhesion of the coating, resulting in a smooth, compact and finer grain size surface; thus, greater corrosion protection efficiency is observed on coated porous substrates.

In the second experiment, nanocomposites are included as protective coatings. The incorporation of $\mathrm{Au}$ and $\mathrm{TiO}_{2}$ nanoparticles into the PPy coating also modified the surface morphology, obtaining less porous coatings than the PPy coating, thus reducing the possibility of electrolyte penetration, and resulting in a further improvement in the corrosion protection of the porous and non-porous substrates.

The most efficient protection results are found in the porous sintered stainless steel with a PPy/DBSA-TiO 2 nanocomposite coating. This is associated with an improvement in the barrier effect, with increased layer stability due to anodic protection, with reduced charge transport due to the nano-size of the $\mathrm{TiO}_{2}$ and with increased surface area for dopant release.

\section{ACKNOWLEDGMENTS}

Financial support by Ministry of Education and Science (Plan Nacional: RTI2018097990-B-I00) and Junta de Castilla y Leon (VA275P18) and (VA044G19) are gratefully acknowledged.

\section{DECLARATION OF COMPETING INTEREST}

The authors declare that they have no known competing financial interests or personal relationships which have, or could be perceived to have, influenced the work reported in this article.

\section{REFERENCES}


1. P. Herrasti, P. Oco, Polypyrrole layers for Steel protection, Appl. Surf. Sci. (2001) 276-284.

2. I.L. Lehr, S.B. Saidman, Corrosion protection of iron by polypyrrole coatings electrosynthesised from a surfactant solution. Corros. Sci. 49 (2007) 2210-2225.

3. R. Balint, N. J. Cassidy, S.H. Cartmell. Conductive polymers: Towards a smart biomaterial for tissue engineering, Acta Biomater. 10 (2014) 2341-2353.

4. C. García Hernández, C. García-Cabezón, C. Medina Plaza, F. Martín-Pedrosa, Y. Blanco, J.A. de Saja, M.L. Rodríguez Méndez, Electrochemical behavior of polypyrrol/AuNP composites deposited by different electrochemical methods: sensing properties towards catechol, Beilstein J. Nanotechnol. 6 (2015) 2052-2061.

5. C. García Hernández, C. García-Cabezón, F. Martín Pedrosa, M.L. Rodríguez Méndez, Analysis of musts and wines by means of a bio-electronic tongue based on tyrosinase and glucose oxidase using polypyrrole/gold nanoparticles as the electron mediator, Food Chem. 289 (2019) 751-756.

6. J.G. Gonzalez-Rodriguez, M.A. Lucio-García, M.E. Nicho,R. Cruz-Silva, M. Casales, E. Valenzuela, Improvement on the corrosion protection of conductive polymers in pemfc environmets by adhesives, J. Power Sources 168 (2007) 184190.

7. T.A. Marín, F.J. Isaza, J.A. Calderón, Electrodeposition of Polypyrrol/Platinum Films, Port.Electrochim. Acta. 27(2009) 397-407.

8. U. Carragher, C.B. Breslin, Polypyrrole doped with dodecylbenzene sulfonate as a protective coating for cooper, Electrochim. Acta. 291 (2018) 362-372.

9. M. Ates, E. Topkaya, Nanocomposites film formation of polyaniline via $\mathrm{TiO} 2, \mathrm{Ag}$ and Zn, and their corrosion protection properties, Prog.Org. Coat.82 (2015) 33-40.

10. I. Sekine, K. Kohara, T. Sugiyma, M. Yuasa, Syntheses of polymerized films on mild steels by electro-oxidation and electroreduction and their corrosion resistance, J. Electrochem. Soc. 139 (1992) 3090-3097.

11. A. Jacques, B. Barthélémy, J. Delhalle, Z. Mekhalif, 1-Pyrrolyl10decylammoniumphosphonate monolayer: a molecular nanolink between electropolymerized pyrrole film and nickel or titanium surfaces, Electroch. Acta, 170 (2015) 218-228.

12. S. Sathiyanarayanan, S. Devi, G. Venkatachari, Corrosion protection of stainless Steel by electropolymerised Pani coating, Prog. Org. Coat. 56 (2006) 114-119.

13. M.B. González, S.B. Saidman, Electrodeposition of bilayered polypyrrole on 316L stainless steel for corrosion prevention, Prog. Org. Coat. 78 (2015) 21-27.

14. M. Rohwerder, A. Michalik, Conducting polymers for corrosion protection: What makes the difference between failure and success?, Electrochim. Acta 53 (2007) 1300-1313.

15. Y. Sun Y. Xia, Polyol Synthesis of Uniform Silver Nanowires: A Plausible Growth Mechanism and the Supporting Evidence, Adv. Mater. 14 (2002) 833

16. G. Cao, Nanostructures and nanomaterials, Synthesis Properties \&Applications, 2004.

17. A.I. López-Lorente, S. Cárdenas, Z.I. González-Sánchez, Effect of synthesis, purification and growth determination methods on the antibacterial and antifungal activity of gold nanoparticles, Mat. Sci. Eng. C, 103 (2019) 109805. 
18. Y. Luo, I. Zhao, Z. Wang, P. Liu, Facile fabrication and selective detection for cysteine of xilan/au nanoparticles composite, 140, Carbohydr. Polym. (2015) 122128.

19. O.V. Molodtsova, I.M. Aristova, D.V. Potorochin, S.V. Babenkov, O.I. Khodos, S.L. Molodtsov, M. Vorokhta, T.Skala, V. Yu. Aristov, Noble metal Nanoparticles in organic matrix, Appl. Surf. Sci. 506 (2020) 144980.

20. R. A.Ahmed, S.A. Fadl-allh, N. El-Bagoury, S. M.F. Gad-El Rab, Improvement of corrosion resistance and antibacterial effect of NiTi orthopedic materials by chitosan and gold nanoparticles, Appl. Surf. Sci, 202 (2014) 300-309.

21. K. Zhang, S. Sharma, Site-Selective, Low-Loading, Au Nanoparticle Polyaniline Hybrid Coatings with Enhanced Corrosion Resistance and Conductivity for Fuel Cells, ACS Sustain. Chem. Eng.5 (2017) 277-286.

22. M. Hosseine, L. Fotouhi, A. Ehsani, M. Naseri, Enhancement of corrosion resistance of polypyrrole using metal oxide nanoparticles: Potentiodynamic and electrochemicalimpedance spectroscopy study, J. Colloid Interf. Sci. 505 (2017) 213-219.

23. M.C. Turkan, M. Weiser, H. Jha, S. Virtanen, Optimization of electrochemical polymerization parameters of polypyrrole on $\mathrm{Mg}-\mathrm{Al}$ alloy (AZ91D) electrodes and corrosion performance, Electrochem. Acta 56 (2011) 5347-5354.

24. M. Mahamoudian, Y. Alia, W. Basirun, M. Eebadi, Effects of different polypyrrole/TiO2 nanocomposite morphologies in polyvinyl butyral coatings for preventing the corrosion of mild steel, Appl. Surf. Sci 268 (2013) 302-311.

25. A. Kumar, N. Rajendran, Influence of zirconia nanoparticles on the surface and electrochemical behaviour of polypyrrole nanocomposite coated 316L SS in simulated body fluid, Surf. Coat. Techn. 213 (2012) 155-166.

26. A. Kumar, A. Madhan; S. Nagarajan, S. Ramakrishna, Electrochemical and in vitro bioactivity of polypyrrole/ceramic nanocomposite coatings on $316 \mathrm{~L}$ SS bioimplants, Mater. Sci. Eng. C 43 (2014) 76-85.

27. A. Kumar, N. Rajendran, Electrochemical aspects and invitro biocompatibility of polypyrrole/TiO2 ceramic nanocomposite coatings on 316LSS for orthopedic implants, Ceram. Int. 39 (2013) 5639-5650.

28. H. Cheshidh, F. Nasirpouri, Cyclic voltammetry deposition of nickel nanoparticles on $\mathrm{TiO} 2$ nanotubes and their enhanced properties for electro-oxidation of methanol, J. Electrochim. Chem.797 (2017) 121-133.

29. W. Chen, et al., Composite-modified anode by $\mathrm{MnO} 2 /$ polypyrrole in marine benthic microbial fuel cells and its electrochemical performance, Int. J. Energy Res. 41 (6) (2017) 845-853.

30. S. Phonsa, P. Sreearunothai, S. Charojrochkul, K. Sombatmankhong, Electrodeposition of $\mathrm{MnO} 2$ on polypyrrole coated stainless steel to enhance electrochemical activities in microbial cells, Solid State Ion. 316 (2018) 125-134.

31. J.R. Davis, ASM Specialty Handbook Stainless Steels, ASM Specialty Handbook, ASM International (2000) OH, USA.

32. M.F. McGuire. Stainless steels for design engineers (2008), ASM International OH USA.

33. P. Lindskog, The future of ferrous PM in Europe, Powder Metall. 47 (2004) 6-9.

34. O. Sandberg, L. Jönson, Advances in Powder Metallurgy, Adv. Mater.Proces. 12 (2003) 37-42. 
35. E Klar, PK Samal, Powder metallurgy stainless steels: processing, microstructures, and properties, ASM International (2007) OH USA.

36. K.H.W. Seah, R. Thampuran, S.H. Teoh, The influence of pore morphology on corrosion, Corrosion Science 40 4/5 (1998) 547-556.

37. C. Garcia, F. Martin, P. de Tiedra, L. García Cambronero, Pitting corrosion behaviour of PM austenitic stainless steels sintered in nitrogen-hydrogen atmosphere, Corros. Sci. 49 (2007) 1718-1736.

38. A.Kocijan, C. Conradi, The corrosion behavior of austenitic and duplex SS in artificial body fluids, Mater. Technol. 44 (2010) 21-24.

39. C. Garcia, F. Martin, Y. Blanco, G. Herranz, Influence of Sinter-Cooling Rate on the Corrosion Behavior of High-Nitrogen Low-Nickel Powder Metallurgy Austenitic Stainless Steel, Corrosion 70 (2014) 1000-1007.

40. ASTM Stardard D 3359, Standard Test Methods for Measuring Adhesion by Tape Test, Method A, ASTM Philadelphia, 1997.

41. ASTM Standard G-5-87, Standard reference test method for making potentiostatic and potentiodynamic anodic polarization measurements, ASTM, Philadelphia, 1993.

42. A. Arrieta, R.J. Vieira, Study of polypyrrole films modified with copper and silver microparticles by electrochemical cementation process. J. Chil. Chem. Soc. 51 (2006) 971-974.

43. A. Arrieta A. R. Tarazona, Study of kinetic formation and the electrochemical behavior of polypyrrole films. J. Chil. Chem. Soc. 54 (2009))14-19.

44. A. Ranella, M. Barberoglou, S. Bakoflanni, C. Fotakis, E. Stratakis, Tuning cell adhesion by controlling, the roughness and wettability of 3D micro/nano silicon structures, Acta Biomat. 6 (2010) 2711-2720.

45. U. Carragher, C.B. Breslin, Polypyrrole doped with dodecylbenzene sulfonate as a protective coating for cooper, Electrochim. Acta 291 (2018) 362-372.

46. A. Nautiyala, M. Qiaob, J. E. Cooka, X. Zhanga, T. H.Nautiyal, High performance polypyrrole coating for corrosion protection and biocidal applications, Appl. Surf. Sci. 427 (2018) 922-930.

47. B. Duran, I. Caknakci, G. Bereket, Role of supporting electrolyte on the corrosion performance of poly/carbazole films deposited on stainless Steel, Corros. Sci. 77(2010) 194-201.

48. C. García-Cabezón, C. GarcíaHernandez, M.L. Rodriguez-Méndez, F. Martín.Pedrosa, A new strategy for corrosion protection of porous stainless steels using polypyrrole films. J. Mat. Sci. Tech. 37 (2020) 85-95.

49. I. Sapurina, S. Fedorava, J. Stejaskal, Langmuir. Surface polymerization and precipitation polymerization of aniline in the presence of sodium tungstate, Langmuir 19 (2003) 7413-7416.

50. J.M. Yeh, C.I. Chen, Y.C. Chen, C.Y.Ma, K.R.Lee, Y. Wei, S. Li, Enhancement of corrosion protection effect of poly(o-ethoxyaniline) via the formation of poly(oethoxyaniline)-clay nanocomposite materials, Polymer 43 (2002) 2729-2736.

51. M. Beikmohammadi, L. Fotouhia, A. Ehsanib, M. Naseria, Potentiodynamic and electrochemical impedance spectroscopy study of anticorrosive properties of p-type conductive polymer/TiO2 nanoparticles, Solid State Ion. 324 (2018) 138-143.

52. M. Hosseini, L.Fotouhi, A. Ehsani, M. Naseri, Enhancement of corrosion resistance of polypyrrole using metal oxide nanoparticles: Potentiodynamic and lectrochemical impedance spectroscopy study. J. Colloid Interfi. Sc 505 (2017) 213-219. 
53. M.G. Mahjani, M. Nasseri, M. Jafarian, Influence of electrosynthesis conditions and $\mathrm{Al} 2 \mathrm{O} 3$ nanoparticles on corrosion protection effect of polypyrrole films, AntiCorros Meth.M. 61 (2014) 146-152. 
Table 1. Tafel parameters of uncoated and conducting polymers coated samples

\begin{tabular}{llllllll}
\hline Sample & Coating & $\begin{array}{l}\mathbf{E}_{\text {corr }} \\
(\mathbf{m V})\end{array}$ & $\begin{array}{l}\boldsymbol{\beta}_{\mathbf{a}} \\
(\mathbf{m V} / \mathbf{d e c a d e})\end{array}$ & $\begin{array}{l}\boldsymbol{\beta}_{\mathbf{c}} \\
(\mathbf{m V} / \mathbf{d e c a d e})\end{array}$ & $\begin{array}{l}\mathbf{I}_{\text {corr }} \\
\left(\boldsymbol{\mu} \mathbf{A} / \mathbf{c m}^{2}\right)\end{array}$ & $\begin{array}{l}\mathbf{R}_{\mathbf{p}} \\
\left(\mathbf{\Omega} / \mathbf{c m}^{2}\right)\end{array}$ & $\begin{array}{l}\text { PE } \\
(\mathbf{\%})\end{array}$ \\
\hline \multirow{4}{*}{ Vacuum } & - & $-334 \pm 10$ & $118.2 \pm 3.5$ & $205.7 \pm 6.2$ & $280.98 \pm 8.4$ & $96.29 \pm 2.9$ & - \\
& PA/Oxalic & $-212 \pm 6.3$ & $253.37 \pm 6.3$ & $152.52 \pm \pm 3.8$ & $95.08 \pm 2.4$ & $273.44 \pm 6.8$ & $64.78 \pm 1.6$ \\
& PPy/DBSA & $-205 \pm 8.2$ & $164.85 \pm 3.3$ & $118.14 \pm 2.4$ & $30.9 \pm 0.6$ & $2143.8 \pm 43$ & $95.50 \pm 1.9$ \\
& PEDOT/PSS & $-222 \pm 4.4$ & $120.77 \pm 3.3$ & $93.50 \pm 2.0$ & $80.62 \pm 2.2$ & $322.48 \pm 8.8$ & $70.14 \pm 1.9$ \\
\hline \multirow{5}{*}{ Nitrogen } & - & $-357 \pm 16$ & $93.28 \pm 3.7$ & $140.62 \pm 5.6$ & $343 \pm 13$ & $75.08 \pm 3.0$ & - \\
& PA/Oxalic & $-106 \pm 3.2$ & $109.53 \pm 1.9$ & $106.01 \pm 1.8$ & $114.7 \pm 2.0$ & $227.41 \pm 3.9$ & $66.98 \pm 1.2$ \\
& PPy/DBSA & $-221 \pm 5.5$ & $51.43 \pm 1.5$ & $84.41 \pm 2.5$ & $27.6 \pm 0.8$ & $943.99 \pm 28$ & $92.08 \pm 2.7$ \\
& PEDOT/PSS & $-41 \pm 1.6$ & $139.76 \pm 4.9$ & $96.38 \pm 2.4$ & $58.7 \pm 2.1$ & $443.96 \pm 1.5$ & $83.09 \pm 2.9$ \\
\hline \multirow{5}{*}{ Wrought } & - & $-340 \pm 17$ & $79.78 \pm 3.5$ & $121.14 \pm 5.4$ & $82.19 \pm 3.7$ & $317.50 \pm 14$ & - \\
& PA/Oxalic & $-110 \pm 4.6$ & $227.26 \pm 6.8$ & $194.54 \pm 5.7$ & $43.77 \pm 1.4$ & $593.92 \pm 18$ & $46.54 \pm 1.4$ \\
& PPy/DBSA & $-166 \pm 4.2$ & $133.72 \pm 2.7$ & $155.88 \pm 3.2$ & $24.35 \pm 0.5$ & $1177.3 \pm 24$ & $73.03 \pm 1.5$ \\
& PEDOT/PSS & $-96 \pm 3.9$ & $166.08 \pm 6.7$ & $156.02 \pm 6.3$ & $47.59 \pm 1.4$ & $552.20 \pm 16$ & $42.50 \pm 1.3$ \\
\hline
\end{tabular}


Table 2. Tafel parameters of nanocomposites coated samples.

\begin{tabular}{|c|c|c|c|c|c|c|c|}
\hline Sample & Coating & $\begin{array}{l}E_{\text {corr }} \\
(\mathrm{mV})\end{array}$ & $\begin{array}{l}\beta_{\mathrm{a}} \\
(\mathrm{mV} / \text { decade })\end{array}$ & $\begin{array}{l}\beta_{\mathrm{c}} \\
(\mathrm{mV} / \mathrm{decade} \\
\quad)\end{array}$ & $\begin{array}{l}I_{\text {corr }} \\
\left(\mu \mathrm{A} / \mathbf{c m}^{2}\right)\end{array}$ & $\begin{array}{l}R_{p} \\
\quad\left(\Omega / \mathrm{cm}^{2}\right)\end{array}$ & $\begin{array}{l}\text { PE } \\
(\%)\end{array}$ \\
\hline \multirow[t]{2}{*}{ Vacuum } & PPy/DBSA-AuNPs & $-118 \pm 4.8$ & $98.95 \pm 3.9$ & $89.87 \pm 1.3$ & $5.04 \pm 1.5$ & $3896.3 \pm 117$ & $97.52 \pm 2.9$ \\
\hline & $\mathrm{PPy} / \mathrm{DBSA}-\mathrm{TiO}_{2} \mathrm{NPs}$ & $-90 \pm 3.2$ & $45.61 \pm 1.4$ & $42.50 \pm 1.3$ & $1.33 \pm 0.4$ & $4517.2 \pm 135$ & $97.87 \pm 2.7$ \\
\hline \multirow[t]{2}{*}{ Nitrogen } & PPy/DBSA-AuNPs & $-230 \pm 9.2$ & $67.08 \pm 2.7$ & $131.2 \pm 5.2$ & $8.50 \pm 0.3$ & $2387.6 \pm 71$ & $84.58 \pm 2.5$ \\
\hline & PPy/DBSA-TiO ${ }_{2} \mathrm{NPs}$ & $-179 \pm 4.5$ & $99.29 \pm 2.8$ & $84.34 \pm 2.4$ & $3.90 \pm 0.2$ & $4482.1 \pm 120$ & $98.32 \pm 2.8$ \\
\hline \multirow[t]{2}{*}{ Wrought } & PPy/DBSA-AuNPs & $-166 \pm 4.9$ & $77.40 \pm 3.0$ & $89.26 \pm 3.5$ & $5.30 \pm 2.1$ & $2967.7 \pm 89$ & $89.30 \pm 2.6$ \\
\hline & $\mathrm{PPy} / \mathrm{DBSA}-\mathrm{TiO}_{2} \mathrm{NPs}$ & $-125 \pm 4.3$ & $50.17 \pm 1.1$ & $59.79 \pm 1.2$ & $2.74 \pm 0.5$ & $3289.2 \pm 66$ & $90.35 \pm 1.8$ \\
\hline
\end{tabular}


Table 3. EIS equivalent circuit parameters of reference and coated samples.

\begin{tabular}{|c|c|c|c|c|c|c|c|c|c|}
\hline Sample & Coating & $\begin{array}{c}\mathbf{R}_{\mathbf{S}} \\
\left(\Omega / \mathbf{c m}^{2}\right)\end{array}$ & $\begin{array}{c}\mathrm{CPE}_{1}-\mathrm{C} \\
\left(10^{-5} \mathrm{~s}^{\mathbf{n}} \mathbf{\Omega}^{-1} \mathrm{~cm}^{-2}\right)\end{array}$ & $\mathrm{CPE}_{1}-\mathrm{n}$ & $\begin{array}{c}\mathbf{R}_{1} \\
\left(\Omega / \mathrm{cm}^{2}\right)\end{array}$ & $\begin{array}{c}\mathrm{CPEC}_{2}-\mathrm{C} \\
\left(10^{-4} \mathrm{~s}^{\mathrm{n}} \mathbf{\Omega}^{-1} \mathrm{~cm}^{-2}\right)\end{array}$ & $\mathrm{CPE}_{2}-\mathrm{n}$ & $\begin{array}{c}\mathbf{R}_{2} \\
\left(\Omega / \mathrm{cm}^{2}\right)\end{array}$ & $\begin{array}{c}\chi^{2} \\
\left(10^{-3}\right) \\
\end{array}$ \\
\hline \multirow{4}{*}{ Nitrogen } & - & $7.5 \pm 0.15$ & $37 \pm 1.5$ & $0.71 \pm 0.03$ & $44.95 \pm 2.2$ & $30 \pm 1.5$ & $0.5 \pm 0.02$ & $2089 \pm 104$ & $0.26 \pm 0.01$ \\
\hline & PPy/DBSA & $12.5 \pm 0.37$ & $6.25 \pm 0.26$ & $0.81 \pm 0.03$ & $1452 \pm 58$ & $7.1 \pm 0.28$ & $0.66 \pm 0.02$ & $23149 \pm 425$ & $1.6 \pm 0.01$ \\
\hline & PPy/DBSA-AuNPs & $11.63 \pm 0.46$ & $2.03 \pm 0.07$ & $0.89 \pm 0.02$ & $6421 \pm 192$ & $1.65 \pm 0.05$ & $0.54 \pm 0.01$ & $30623 \pm 418$ & $1.7 \pm 0.01$ \\
\hline & PPy/DBSA-TiO2NPs & $15.08 \pm 0.75$ & $0.92 \pm 0.02$ & $0.88 \pm 0.02$ & $4260 \pm 85$ & $0.55 \pm 0.01$ & $0.35 \pm 0.01$ & $60833 \pm 608$ & $1.0 \pm 0.01$ \\
\hline
\end{tabular}




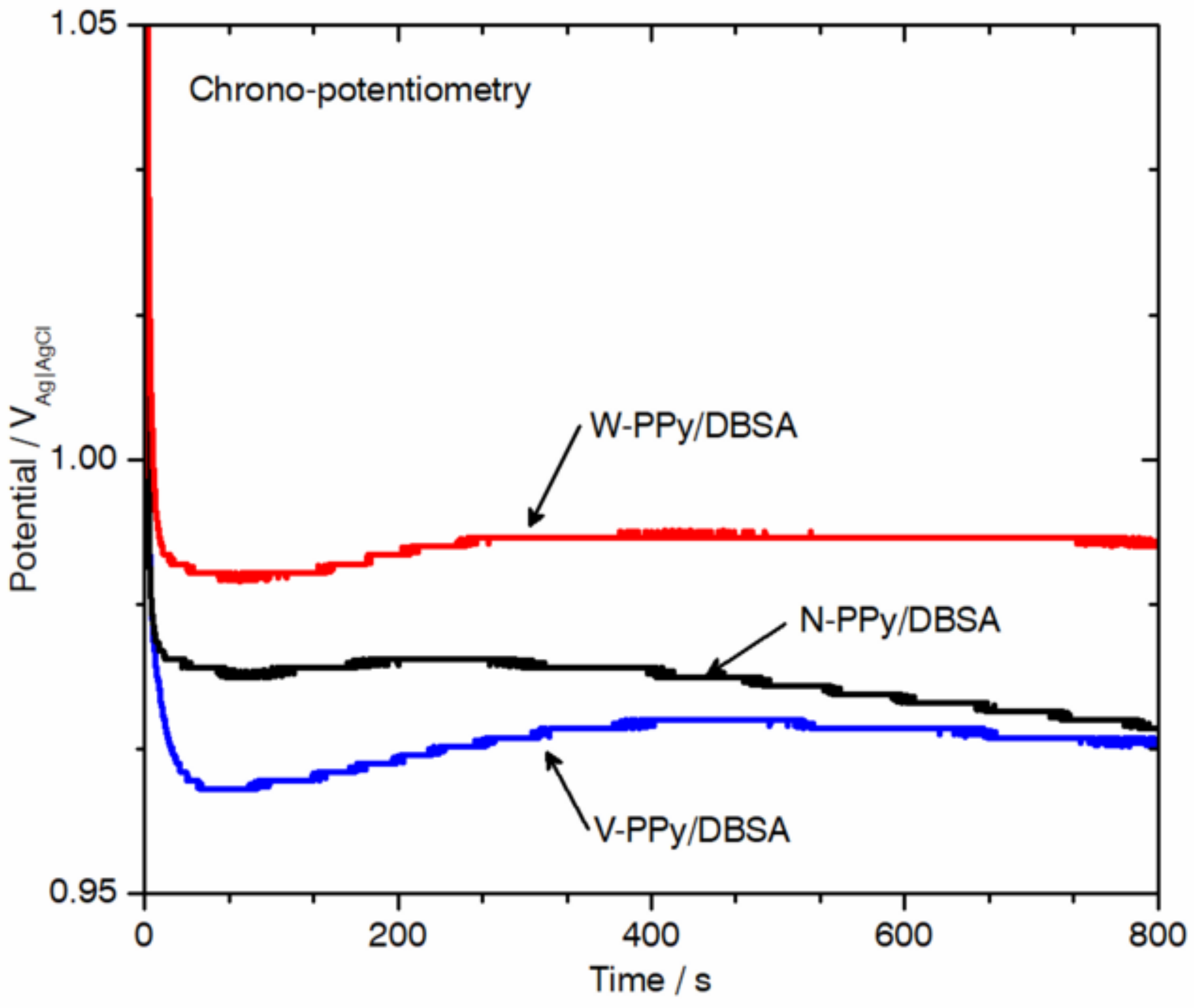




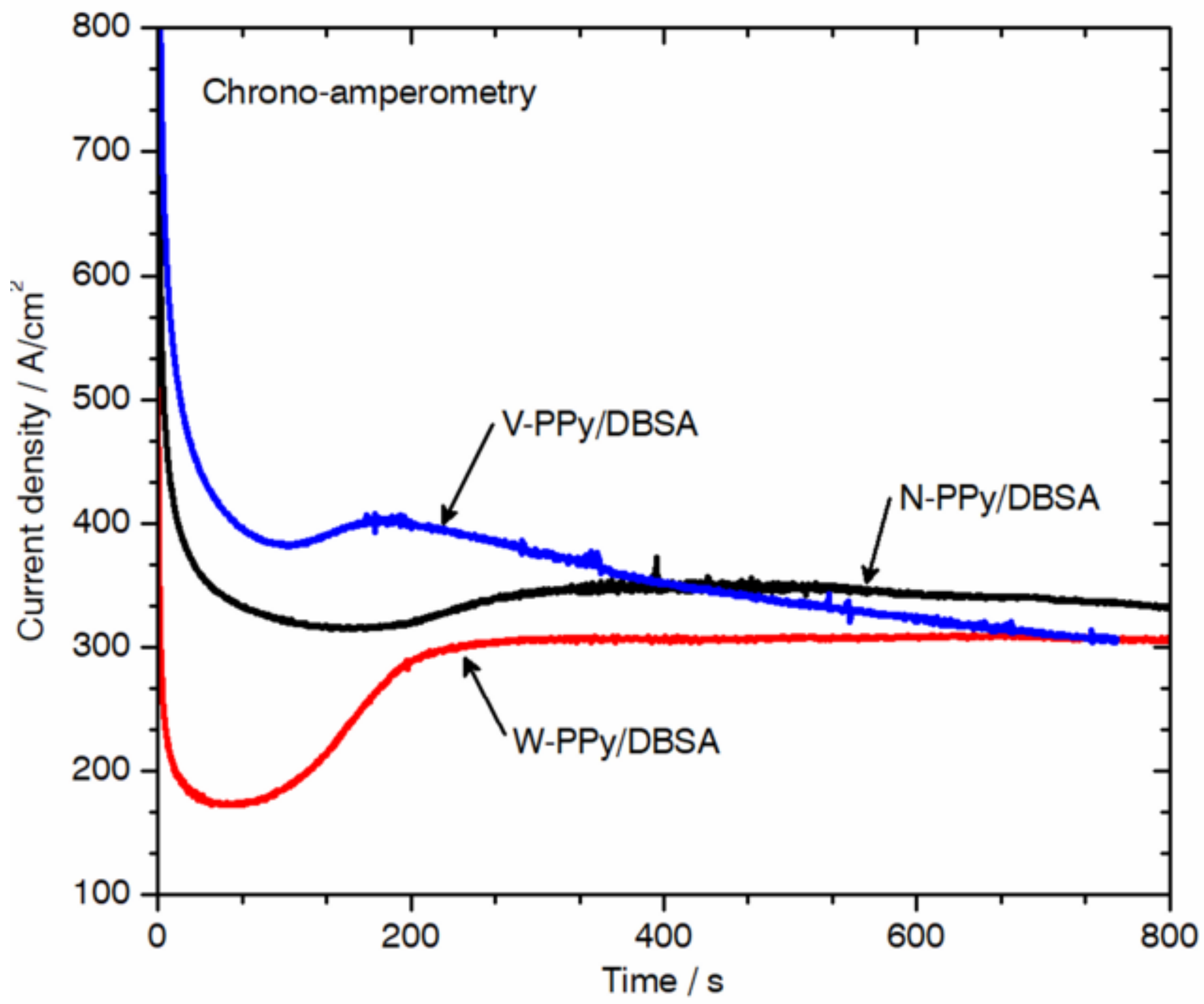


Click here to download high resolution image

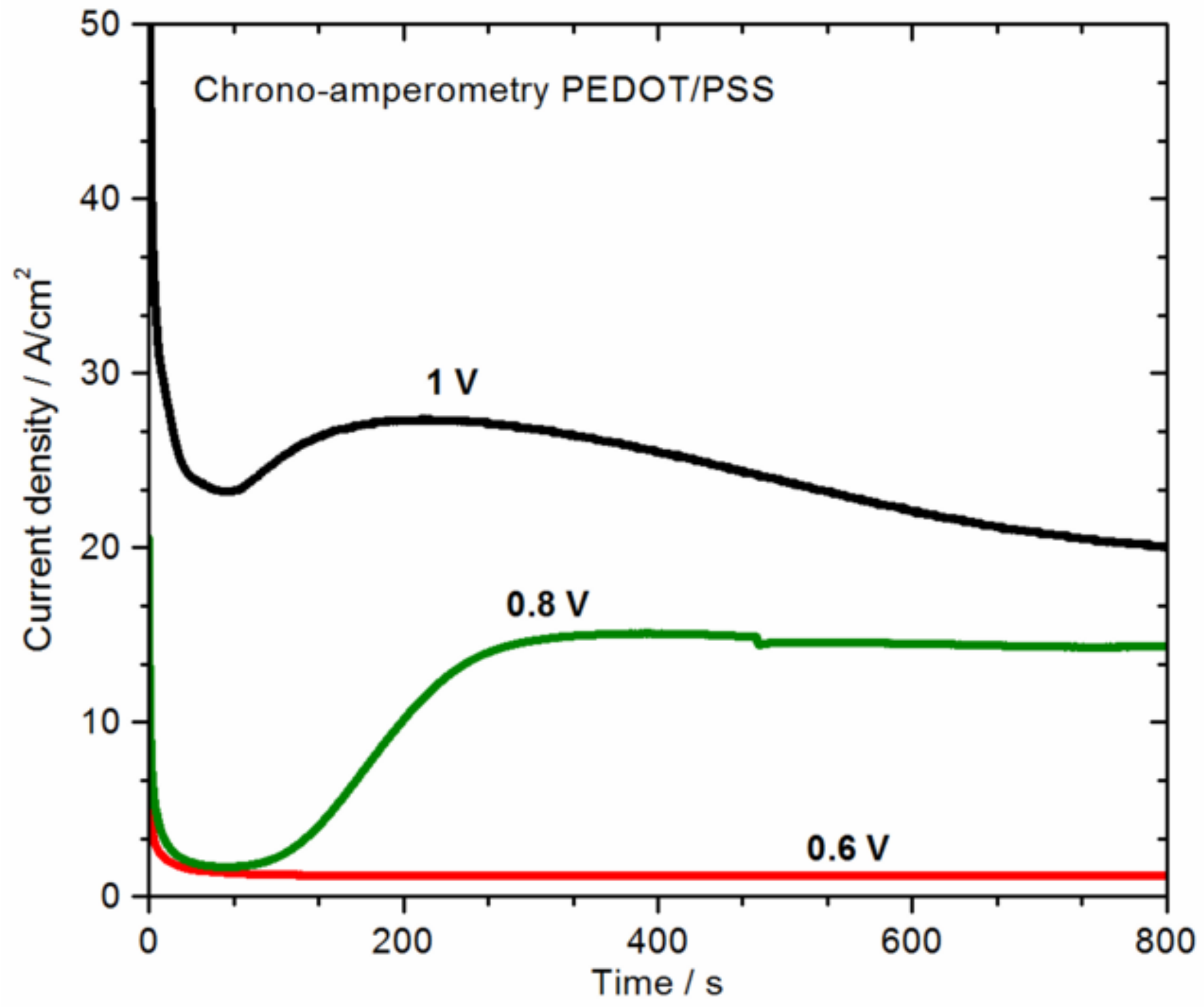


Click here to download high resolution image

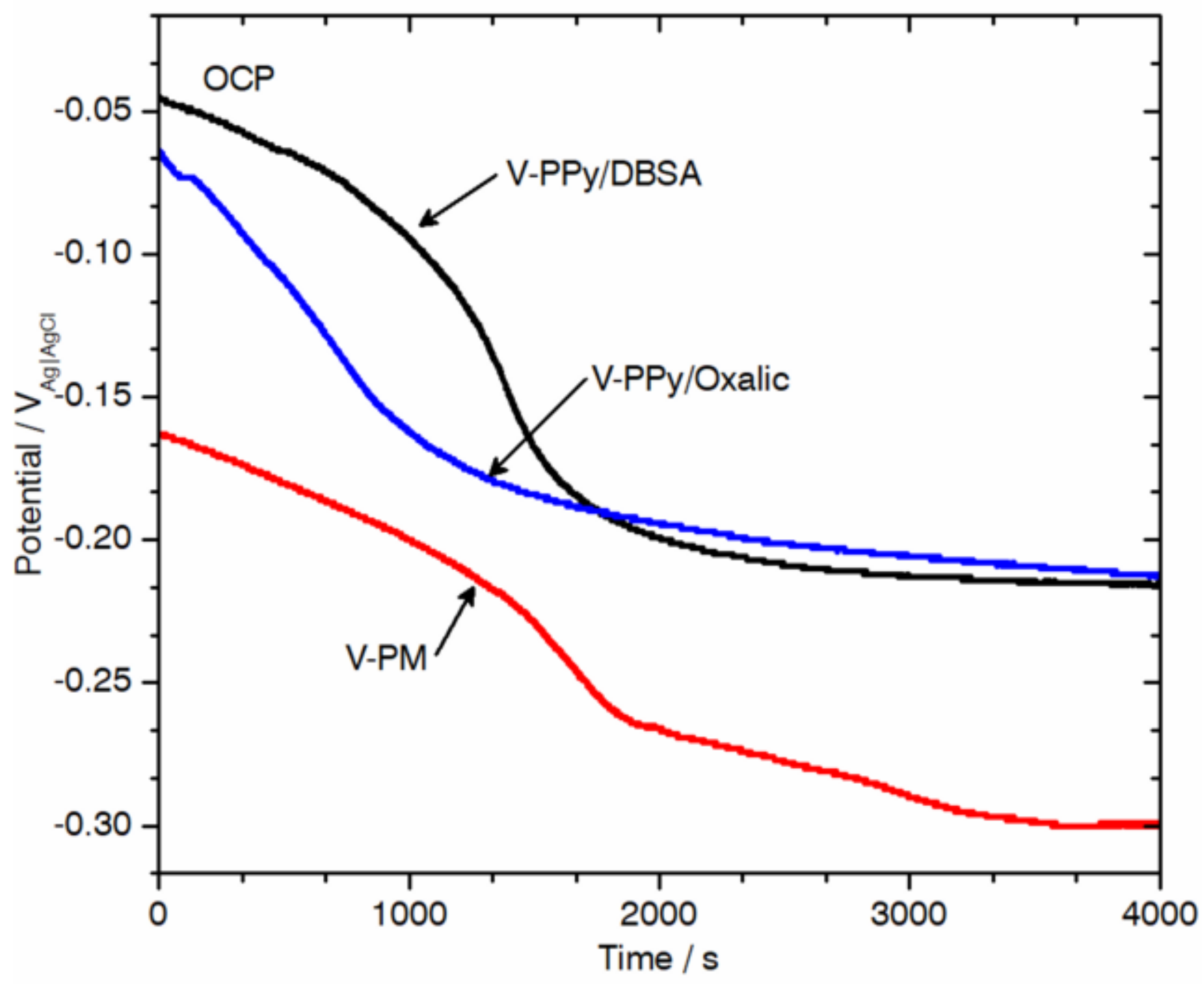




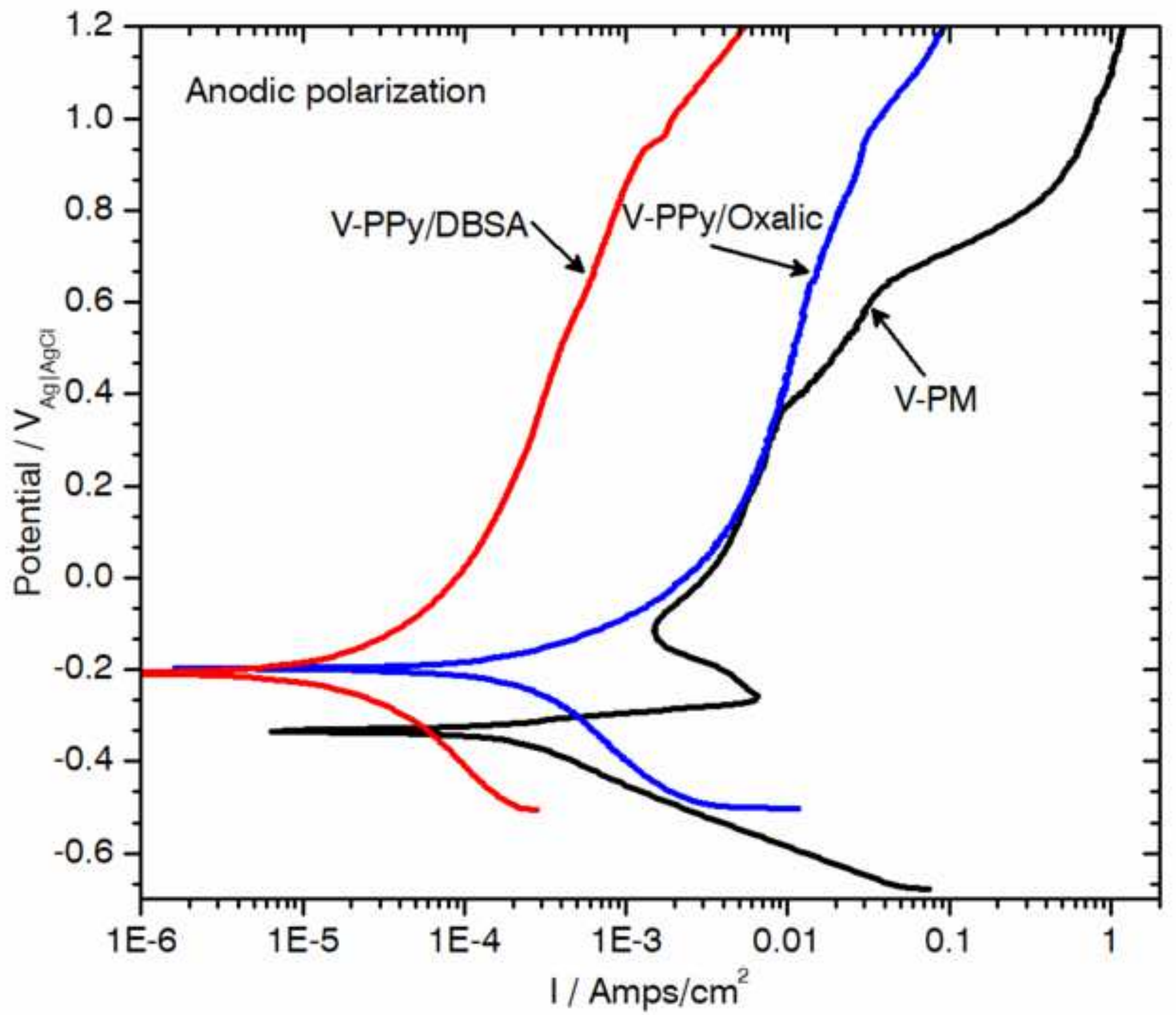




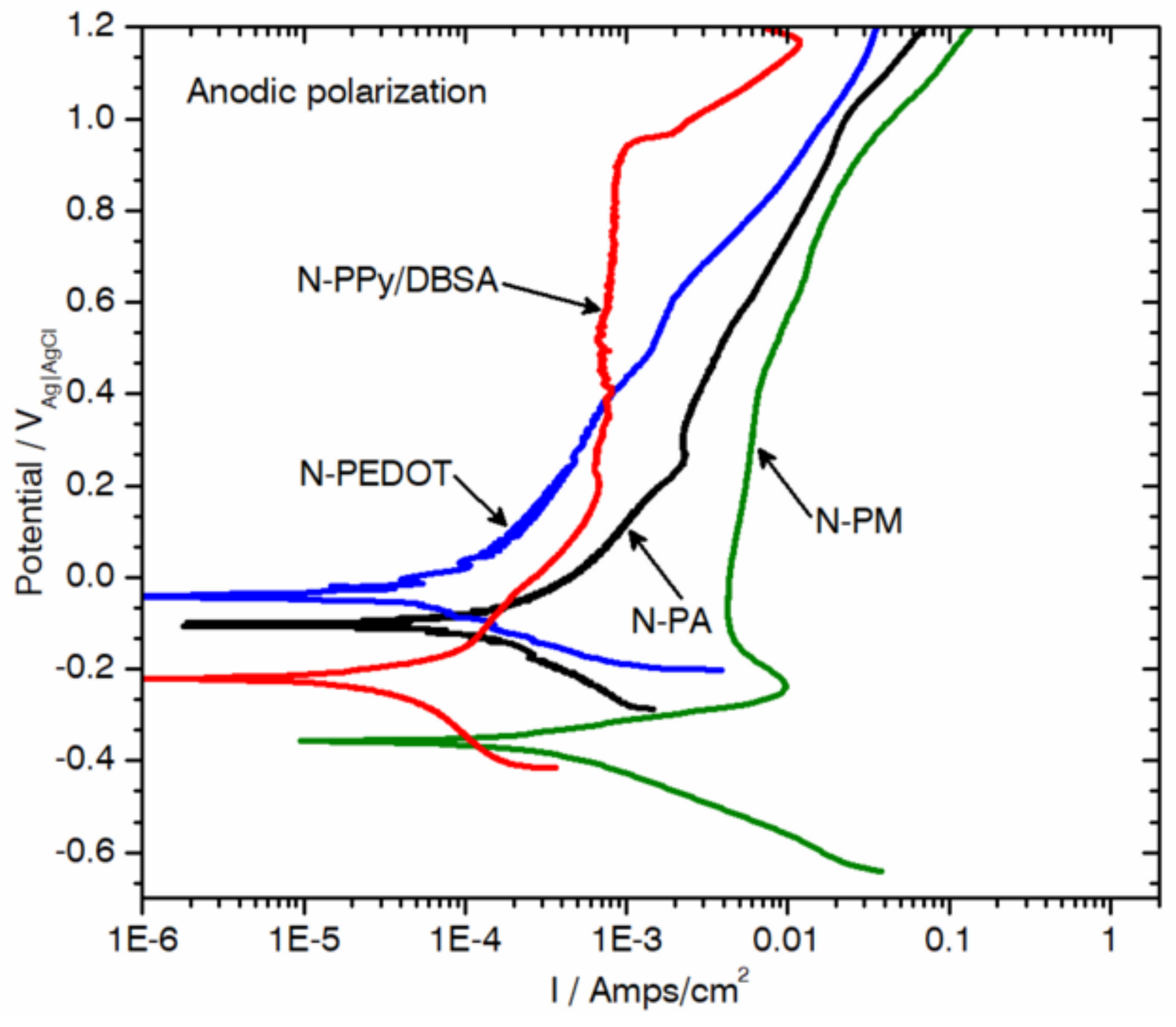

fig 2 cr0.tif
Click here to download high resolution image 


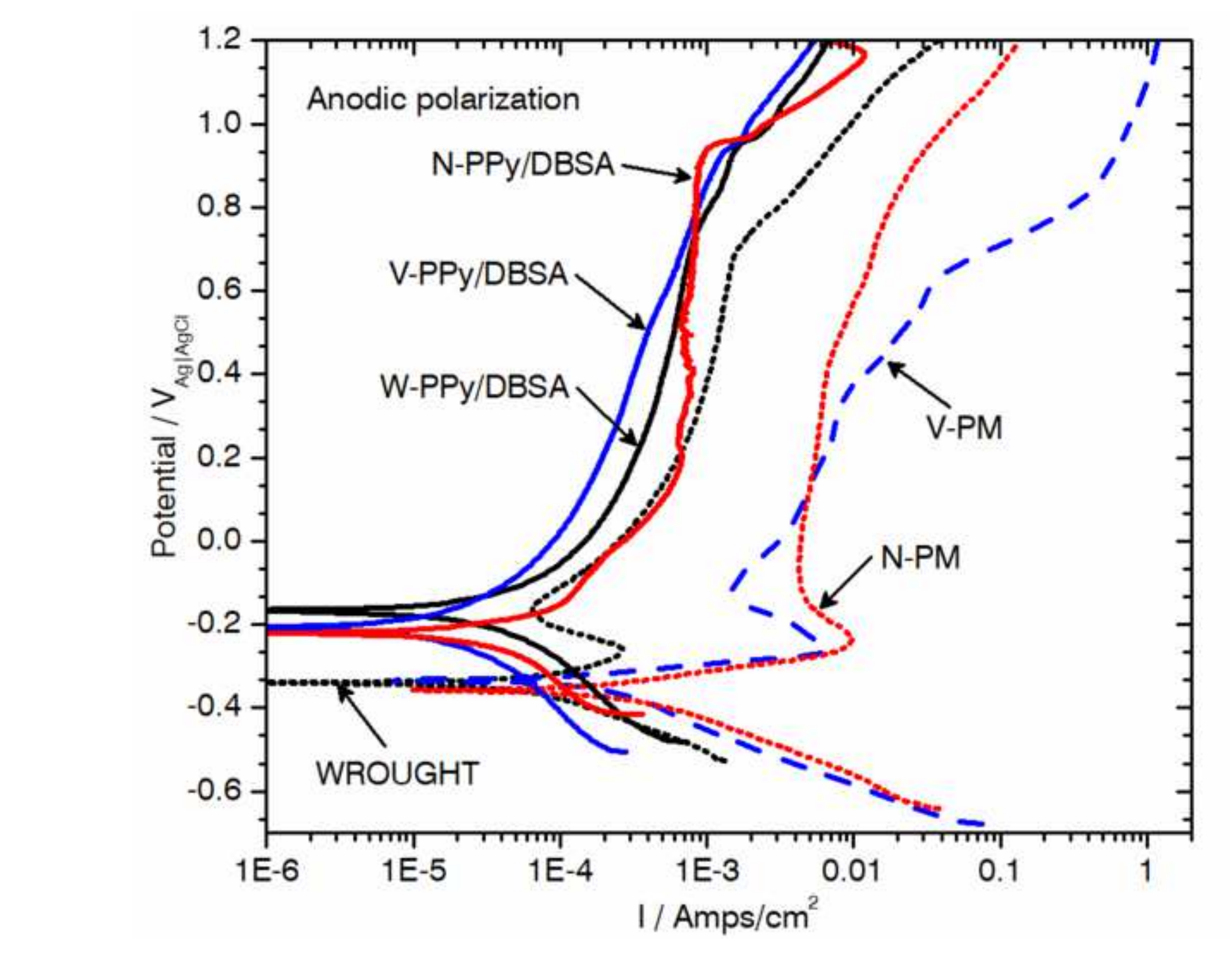


Click here to download high resolution image

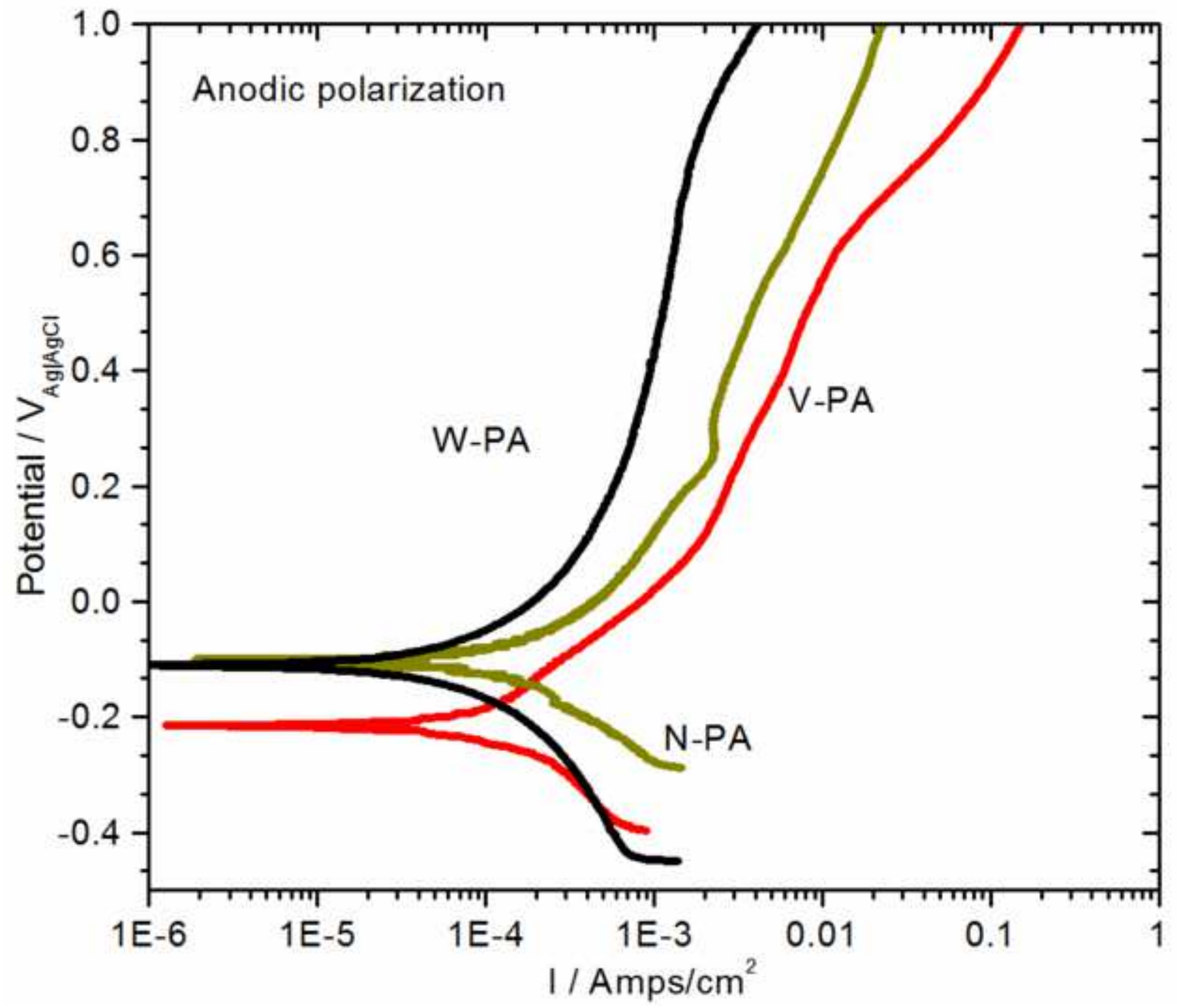


Figure 3a

Click here to download high resolution image

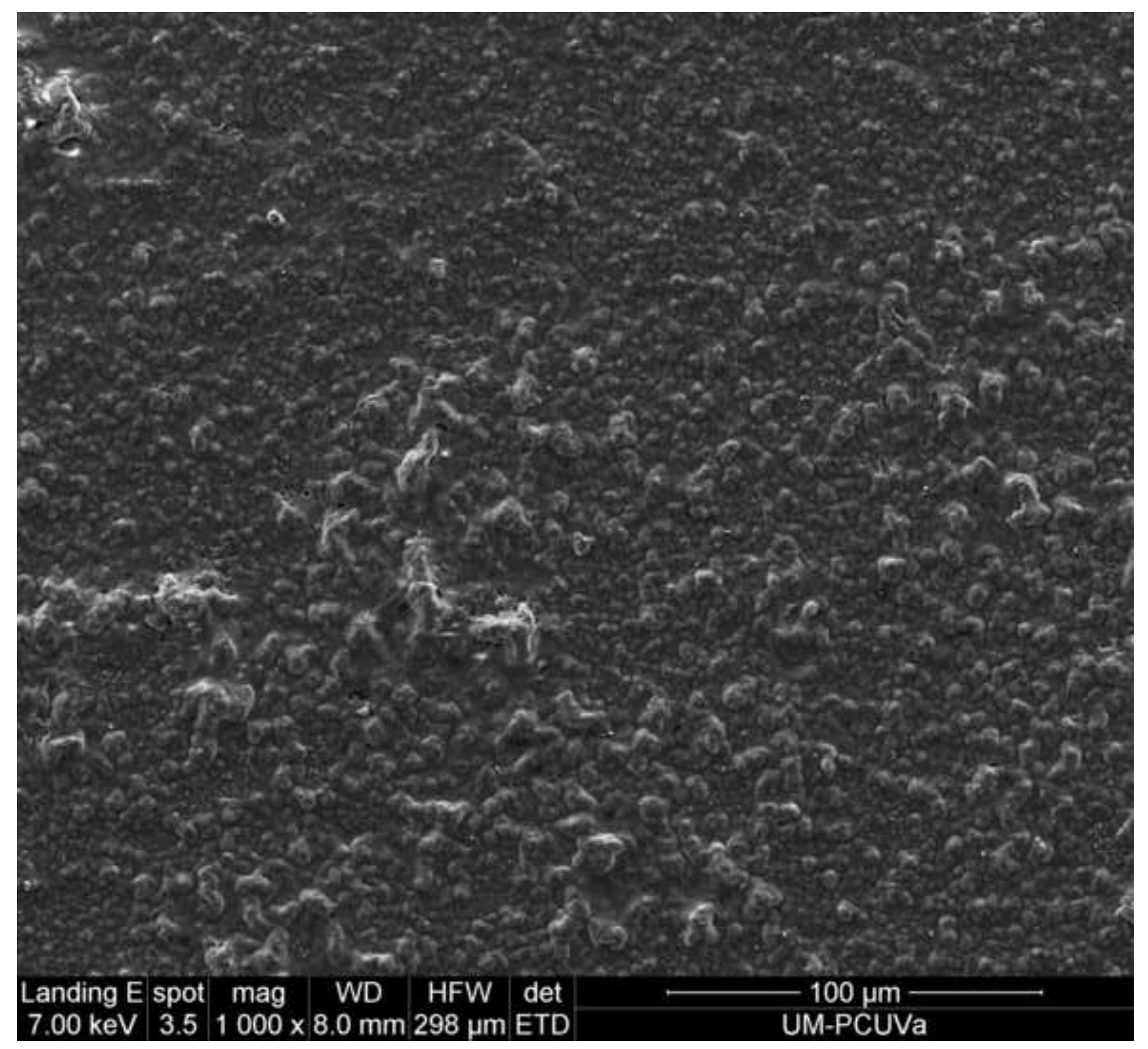

$7.00 \mathrm{keV} 3.51000 \times 8.0 \mathrm{~mm} 298 \mu \mathrm{m}$ ETD

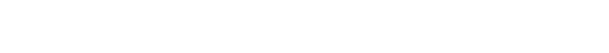

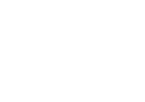


Click here to download high resolution image

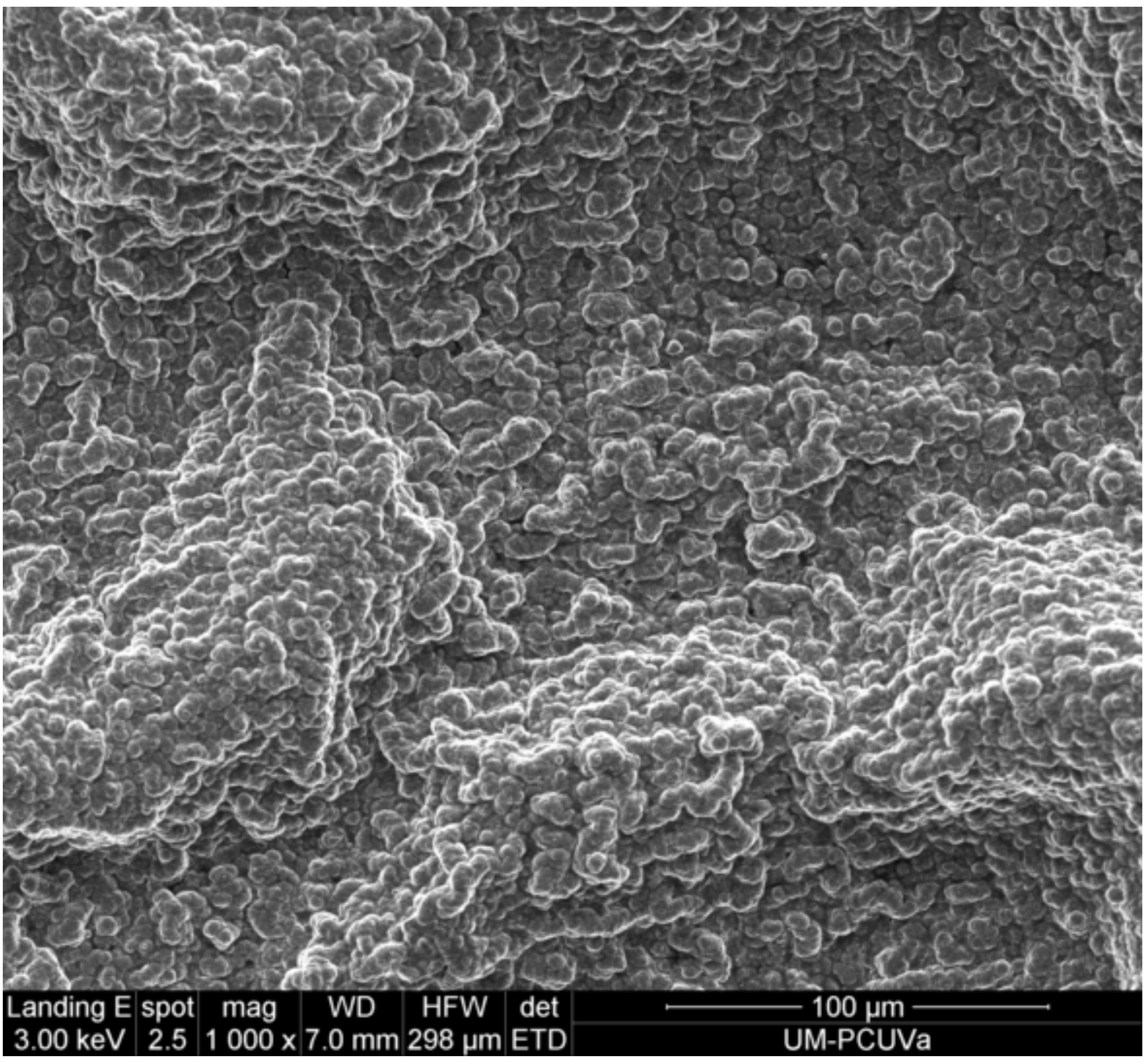

UM-PCUVa 
Click here to download high resolution image
clifa 3 cro.tif

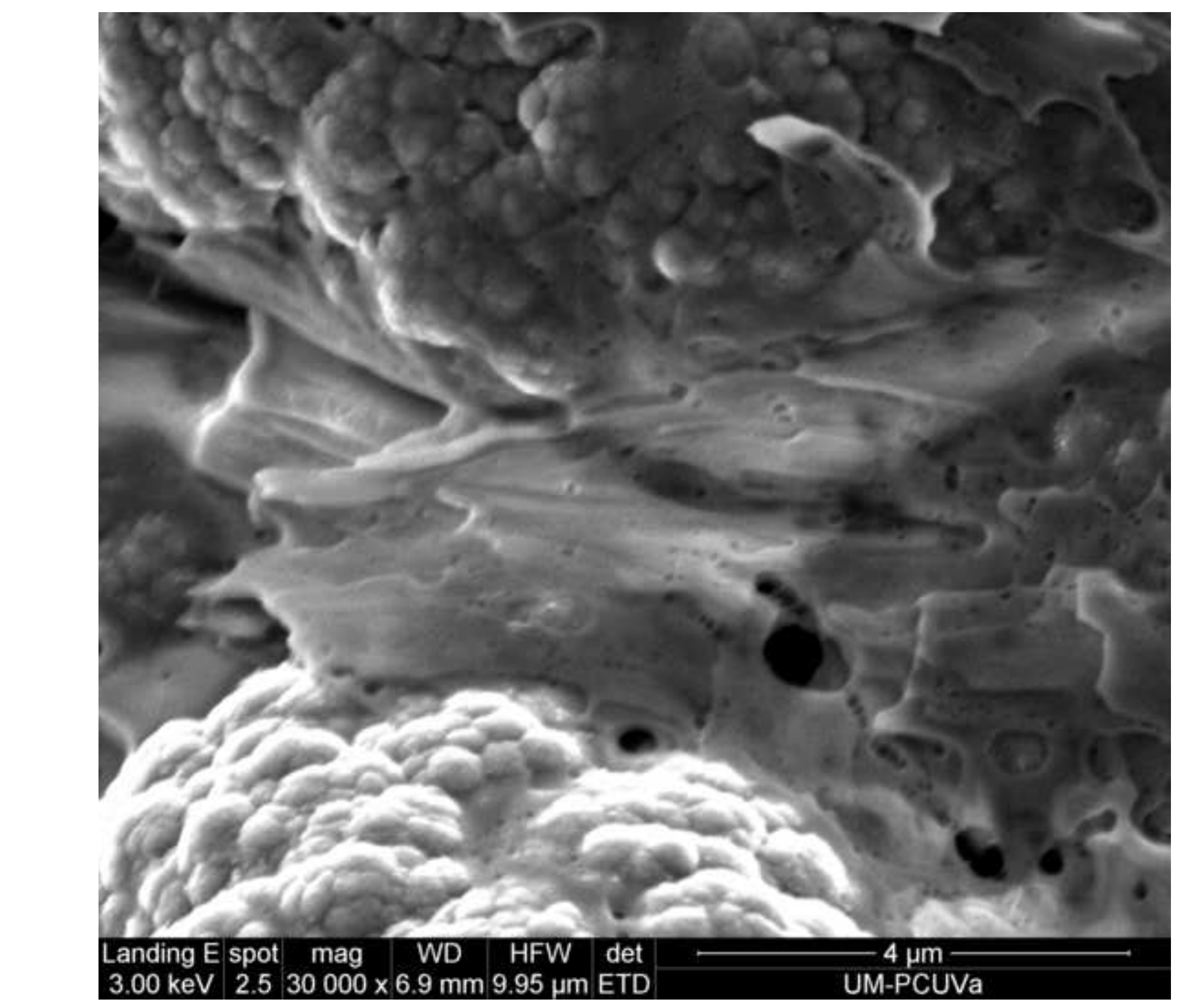

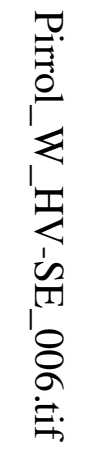

.

\section{UM-PCUVa}

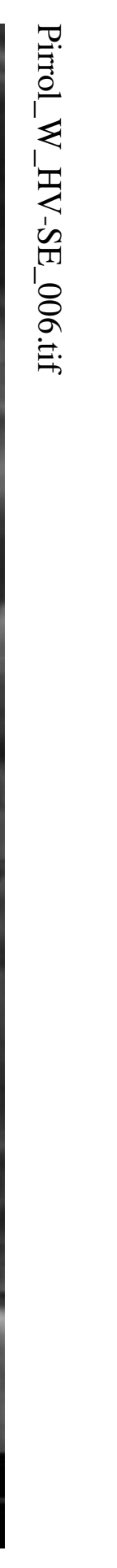




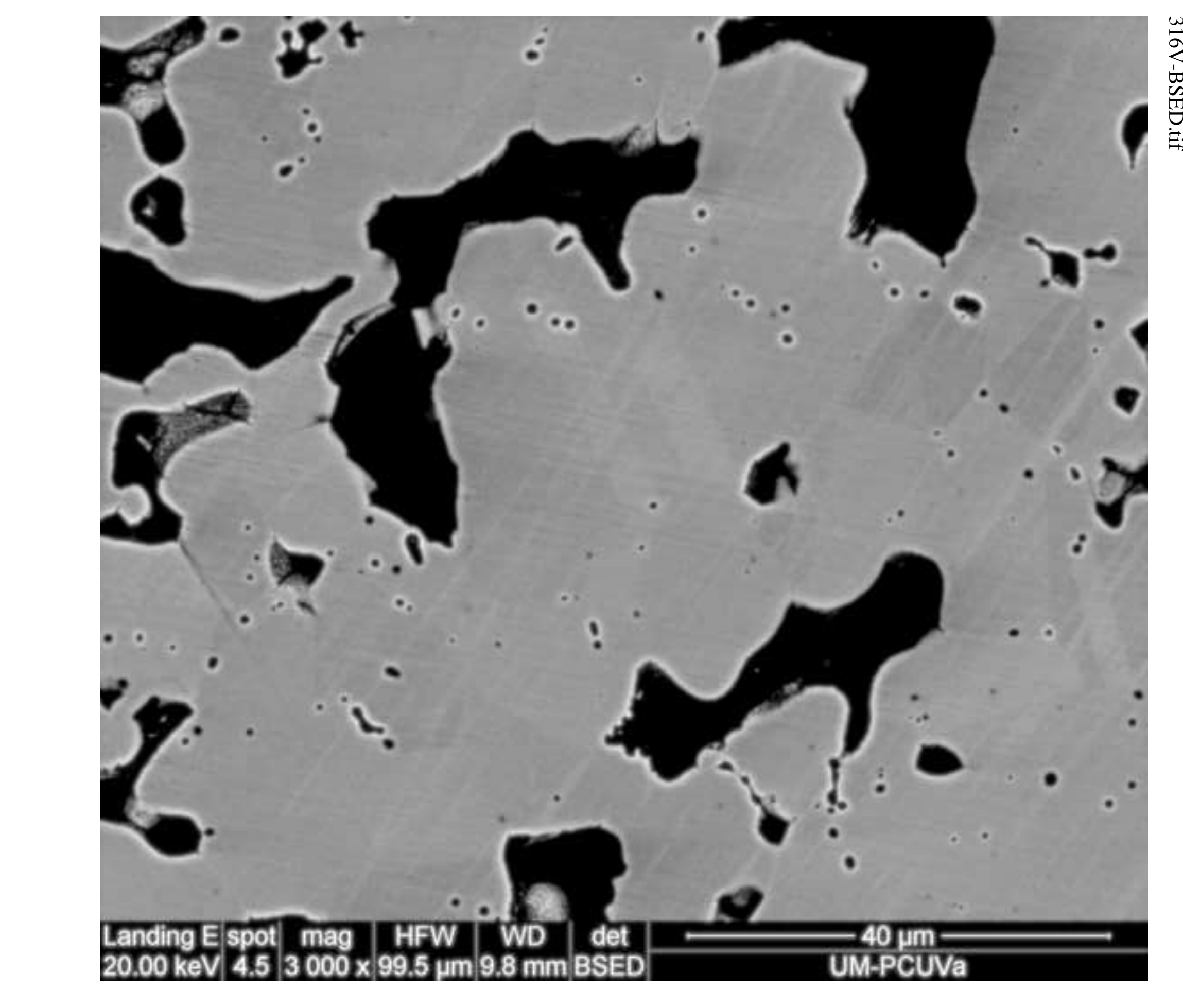

\section{.}




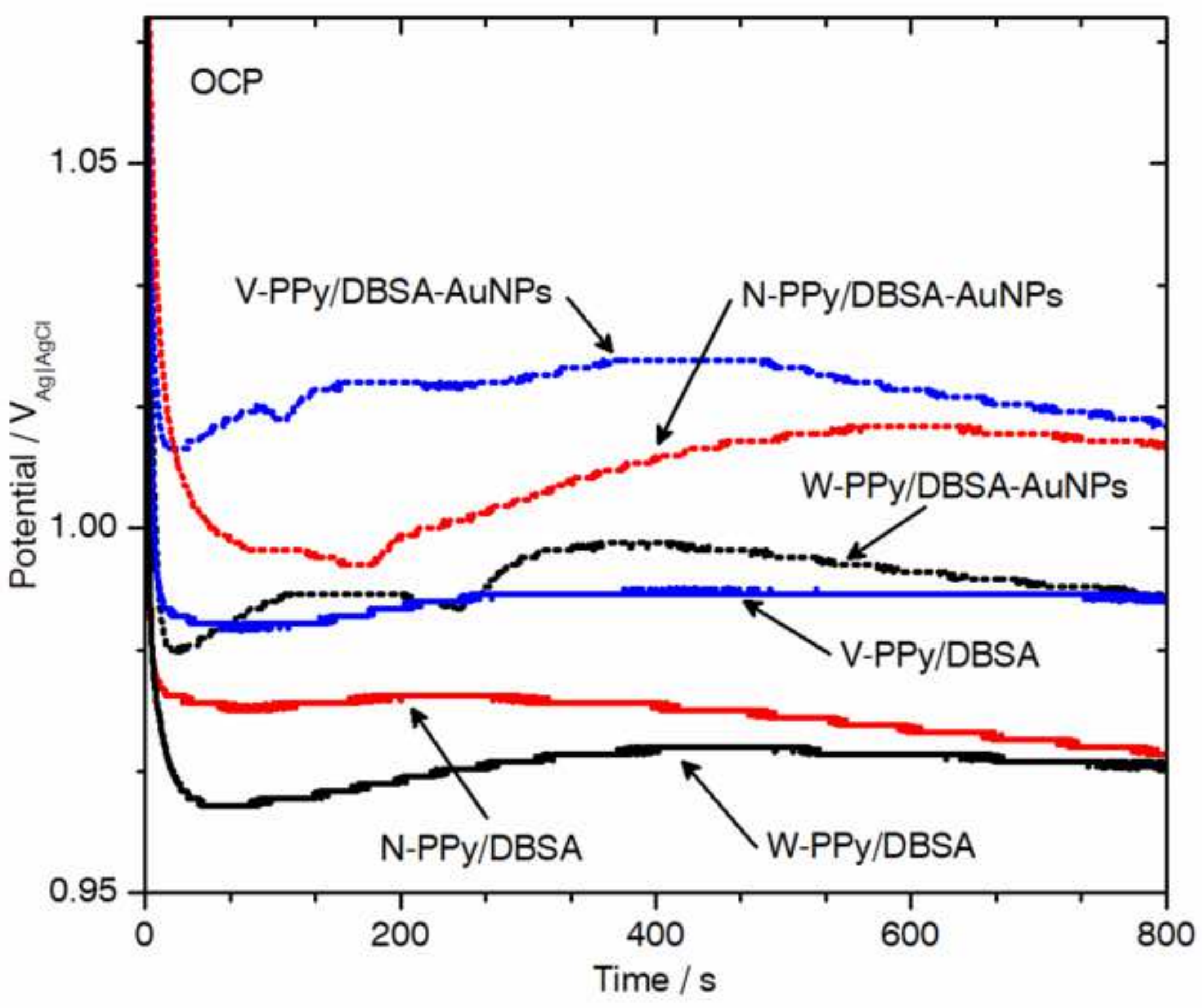




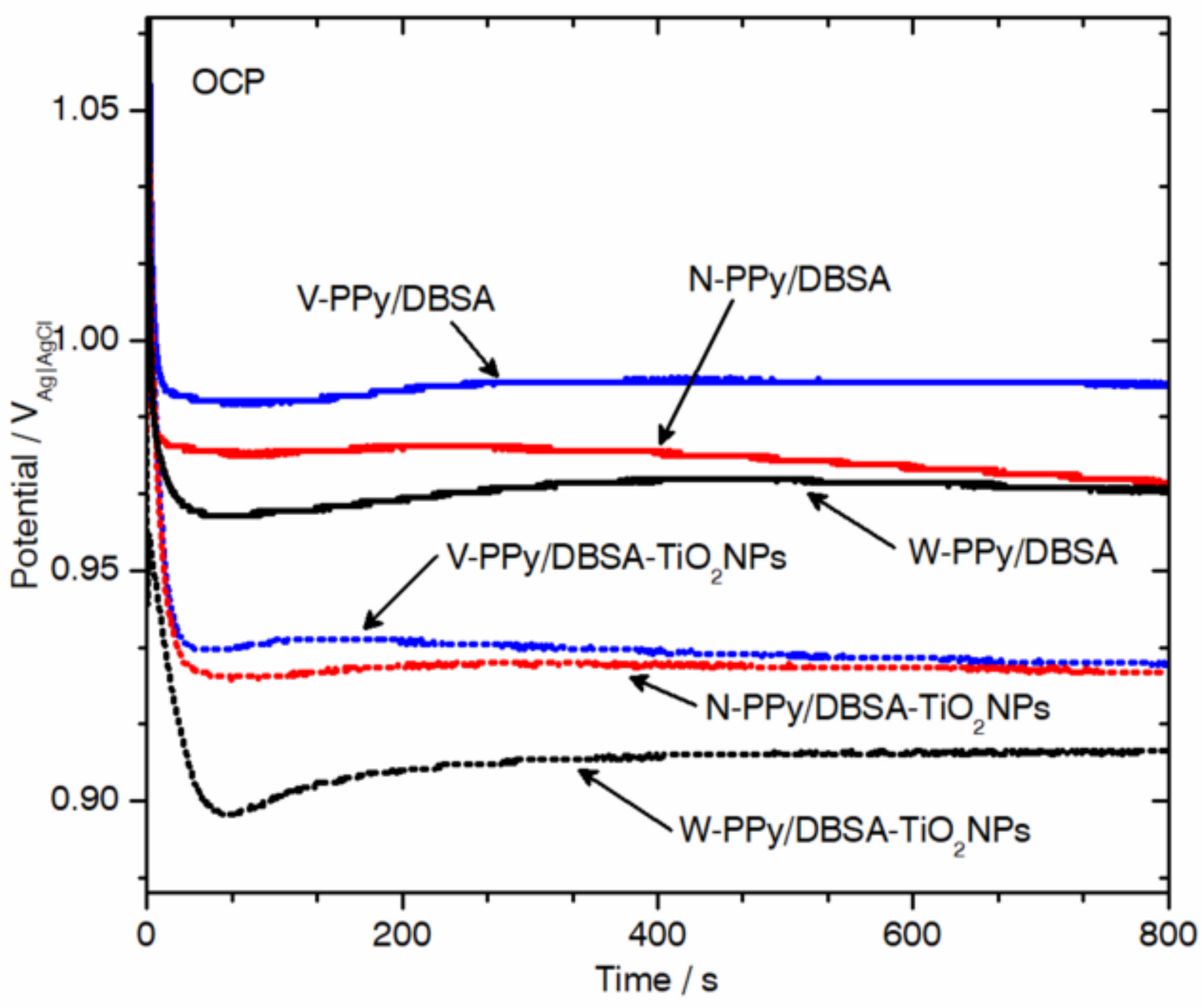



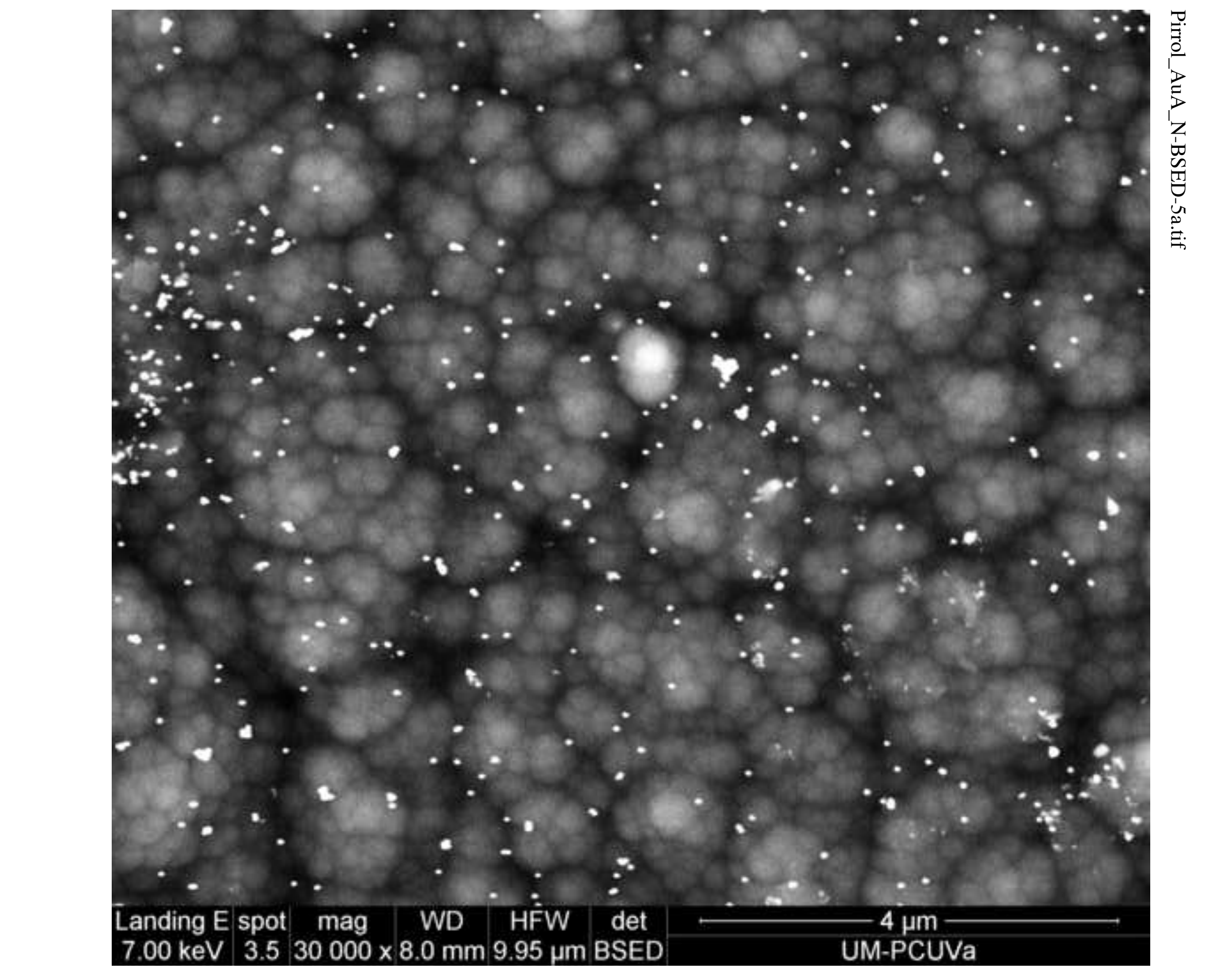


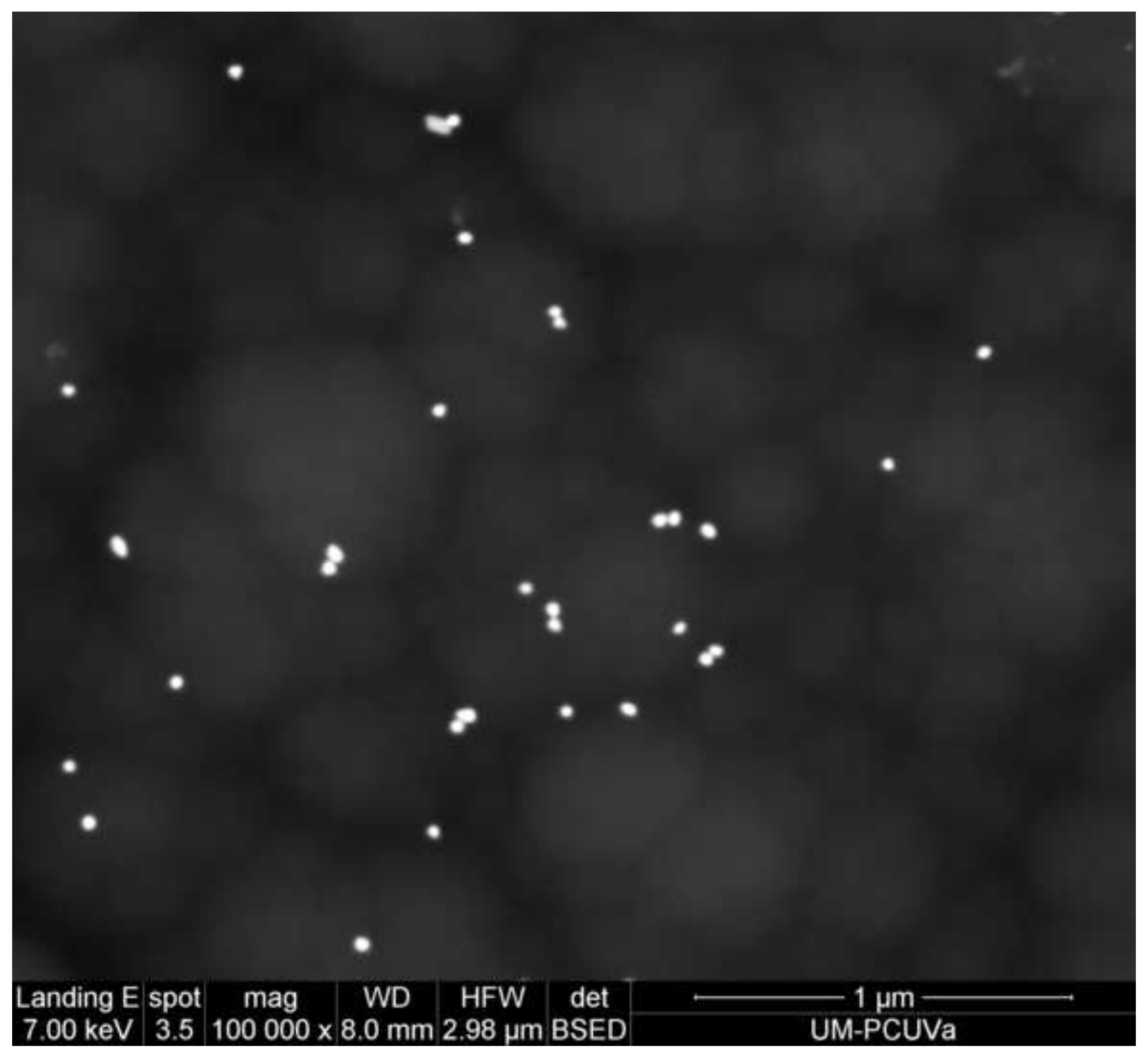

Click here 

fig 5er0.tif

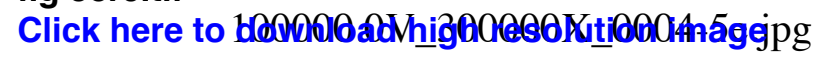

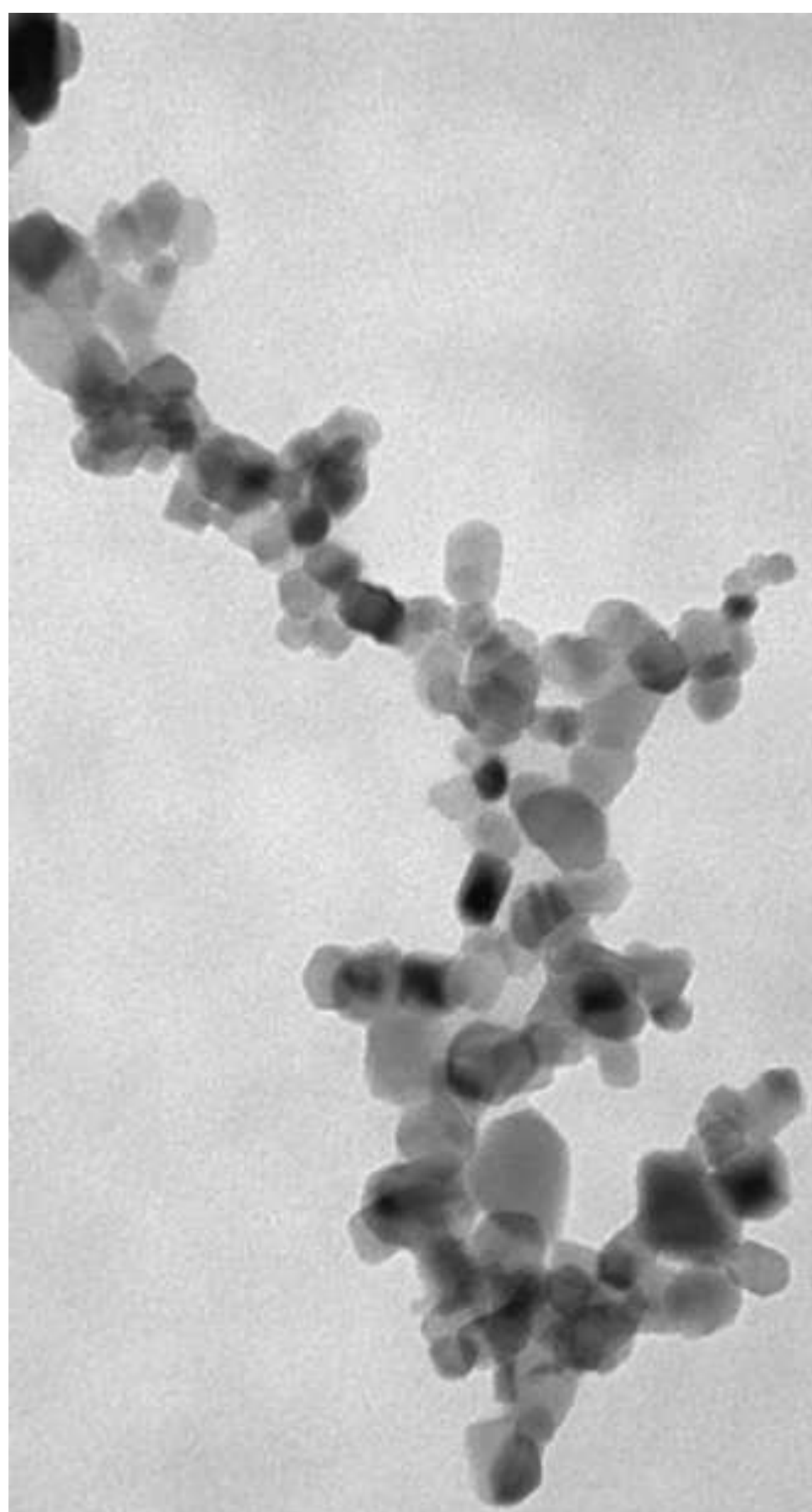




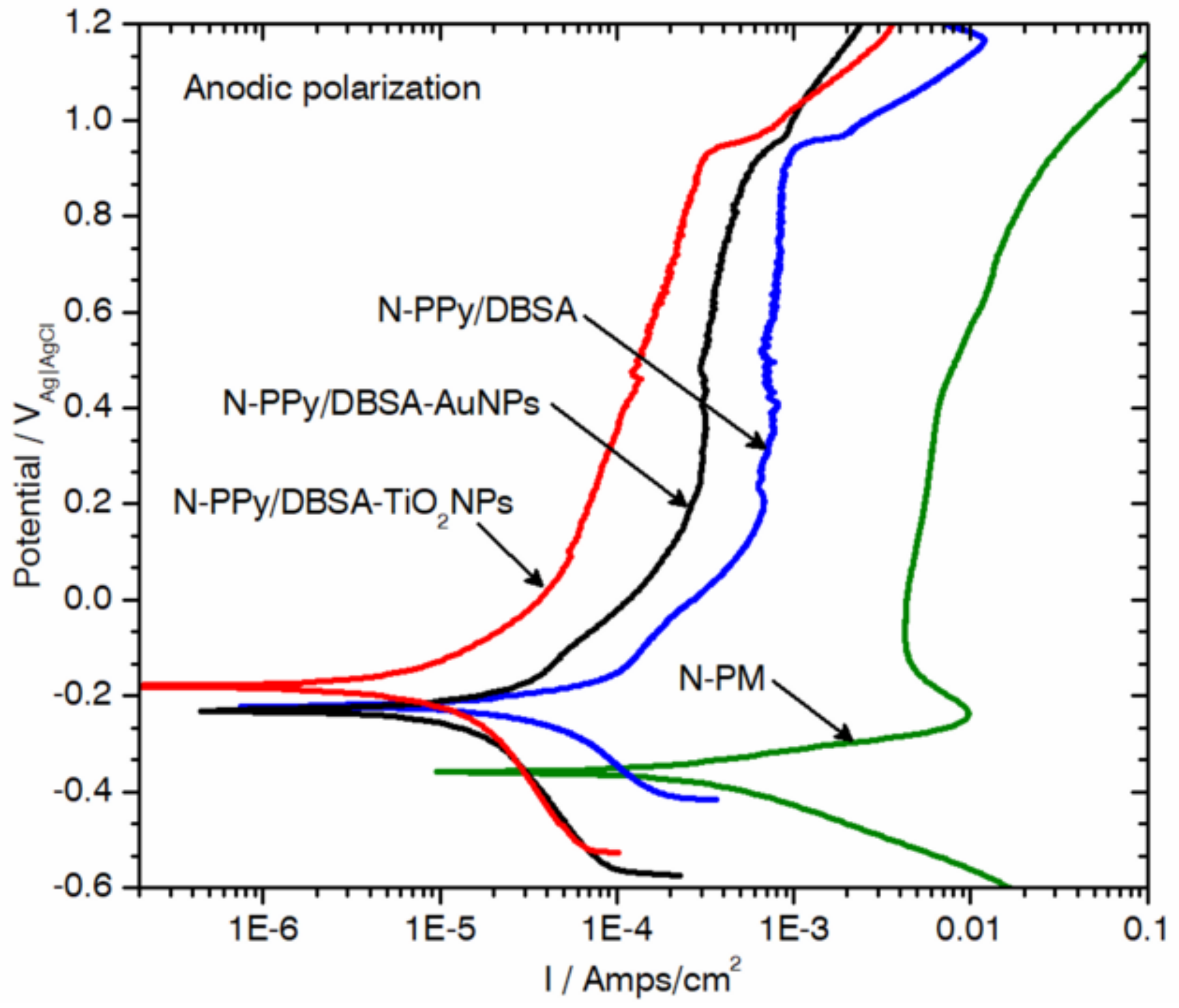




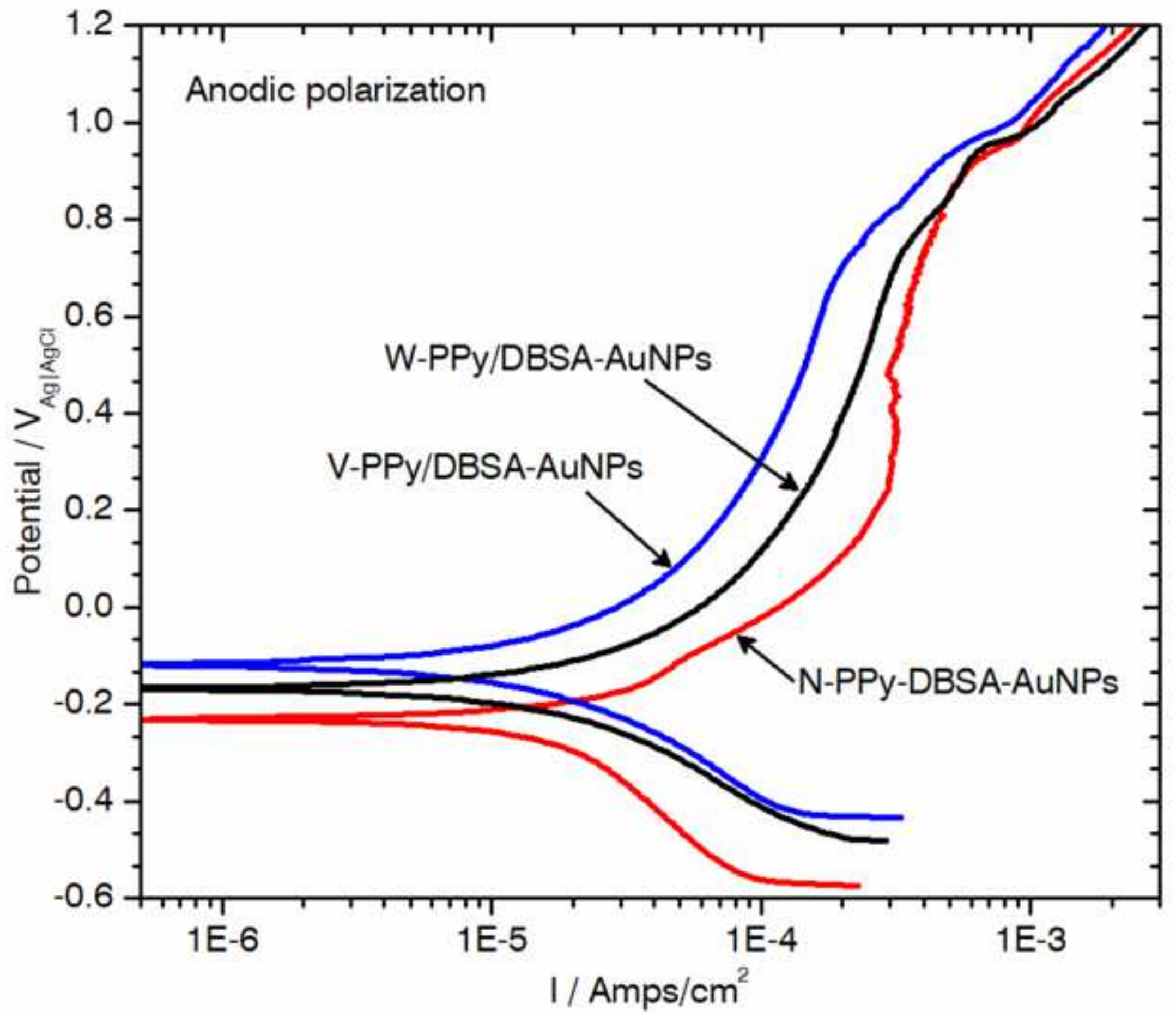




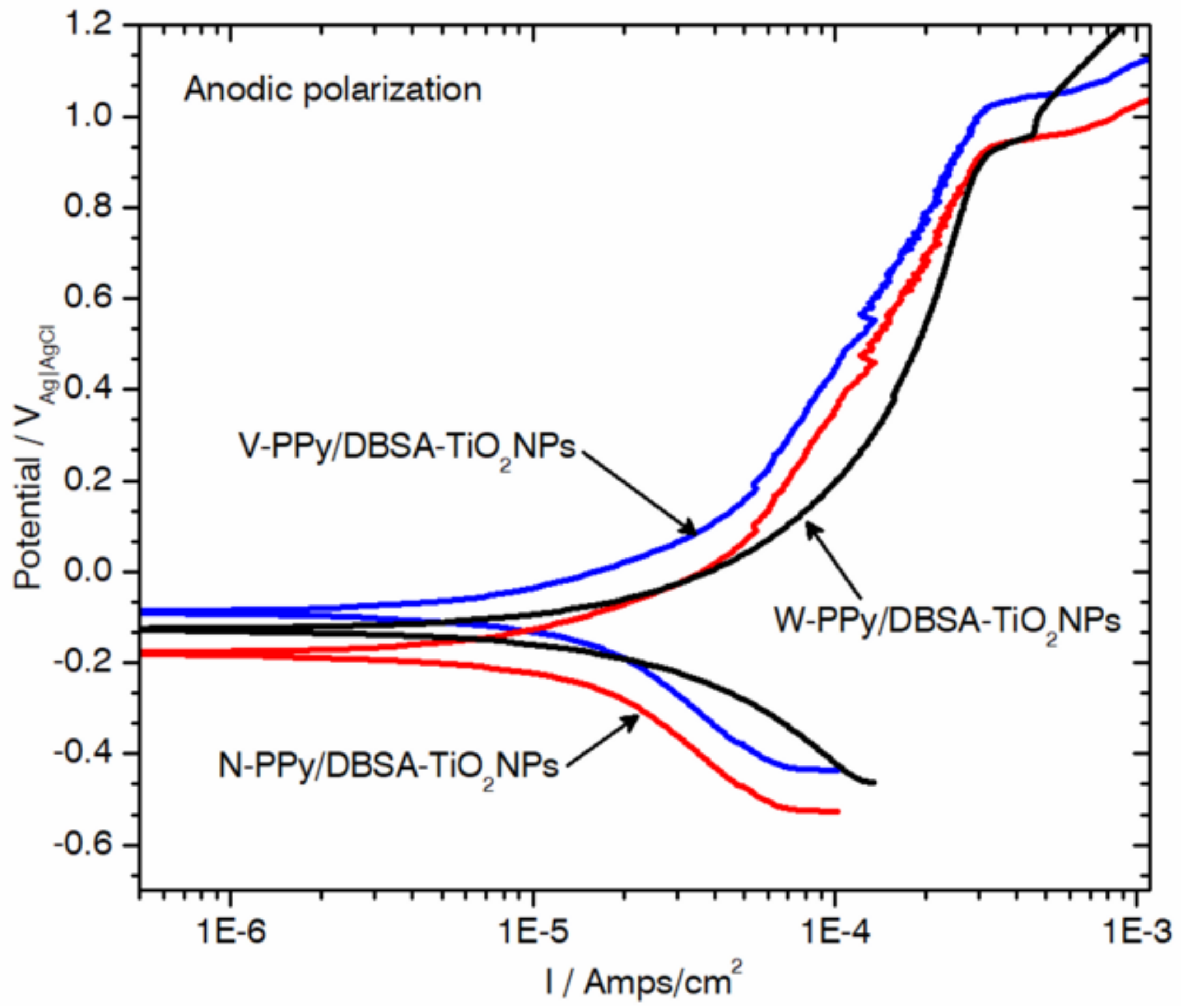




\section{gura 3ar0.tif}

Click here to download high resolution image
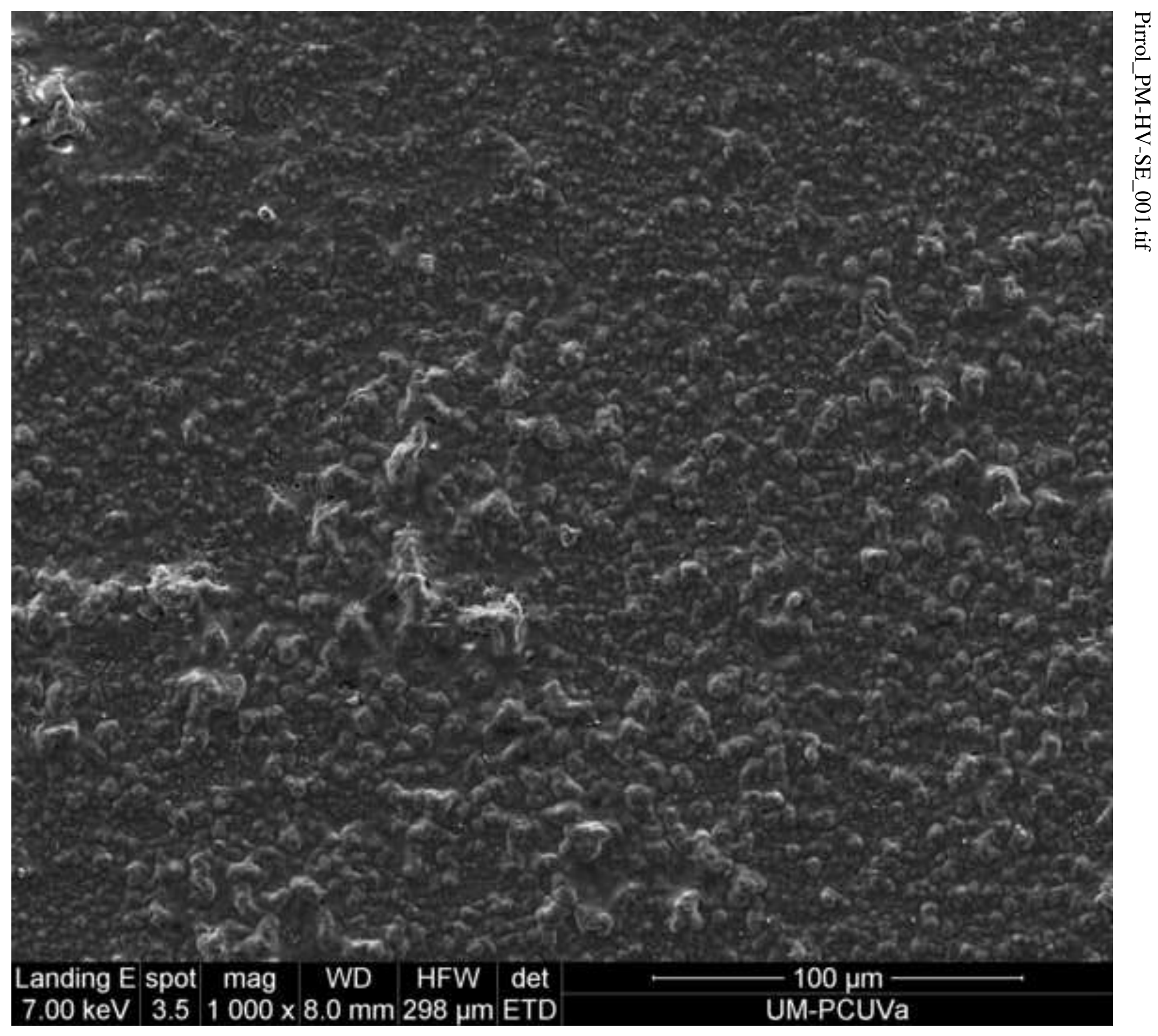


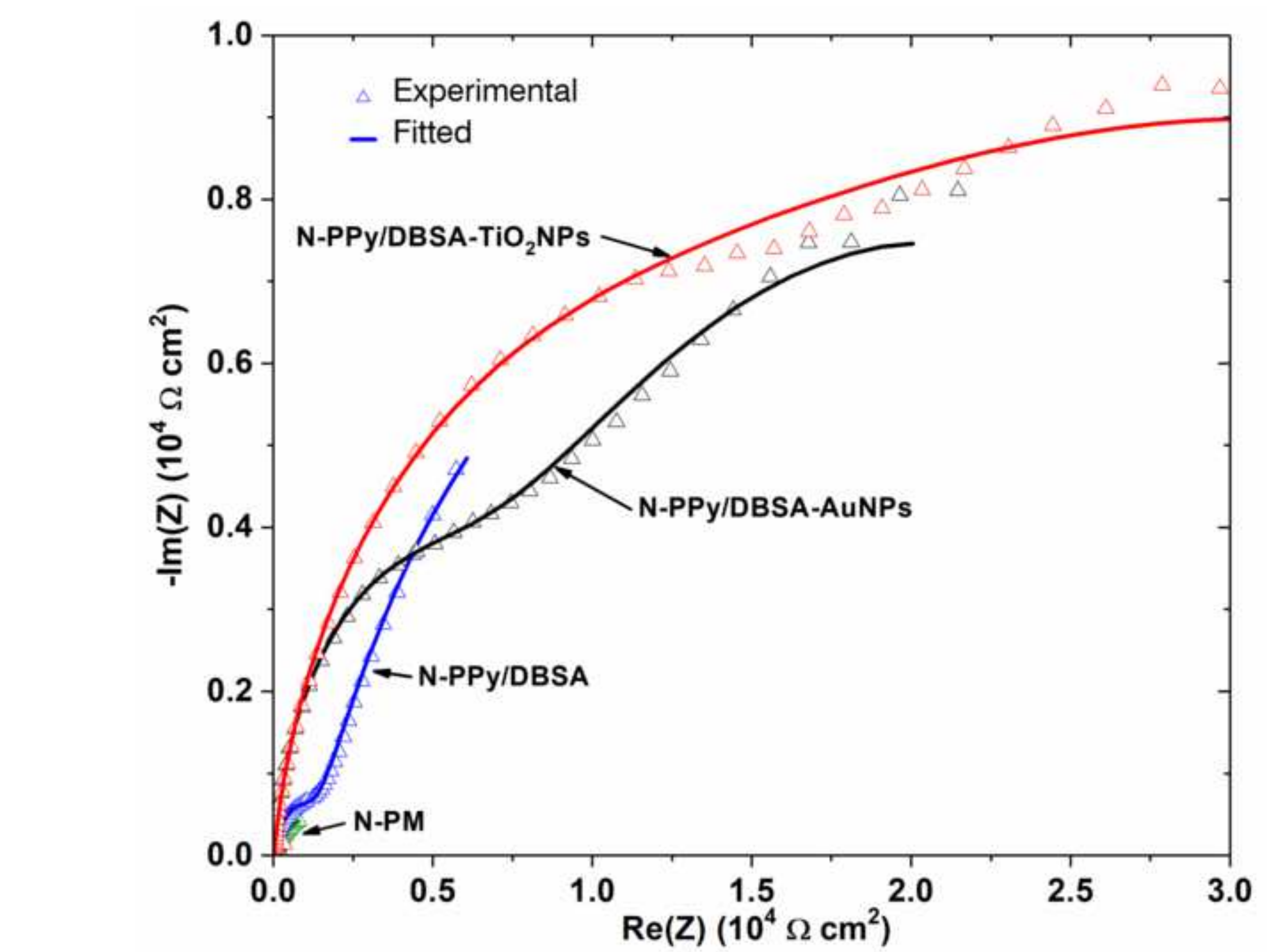




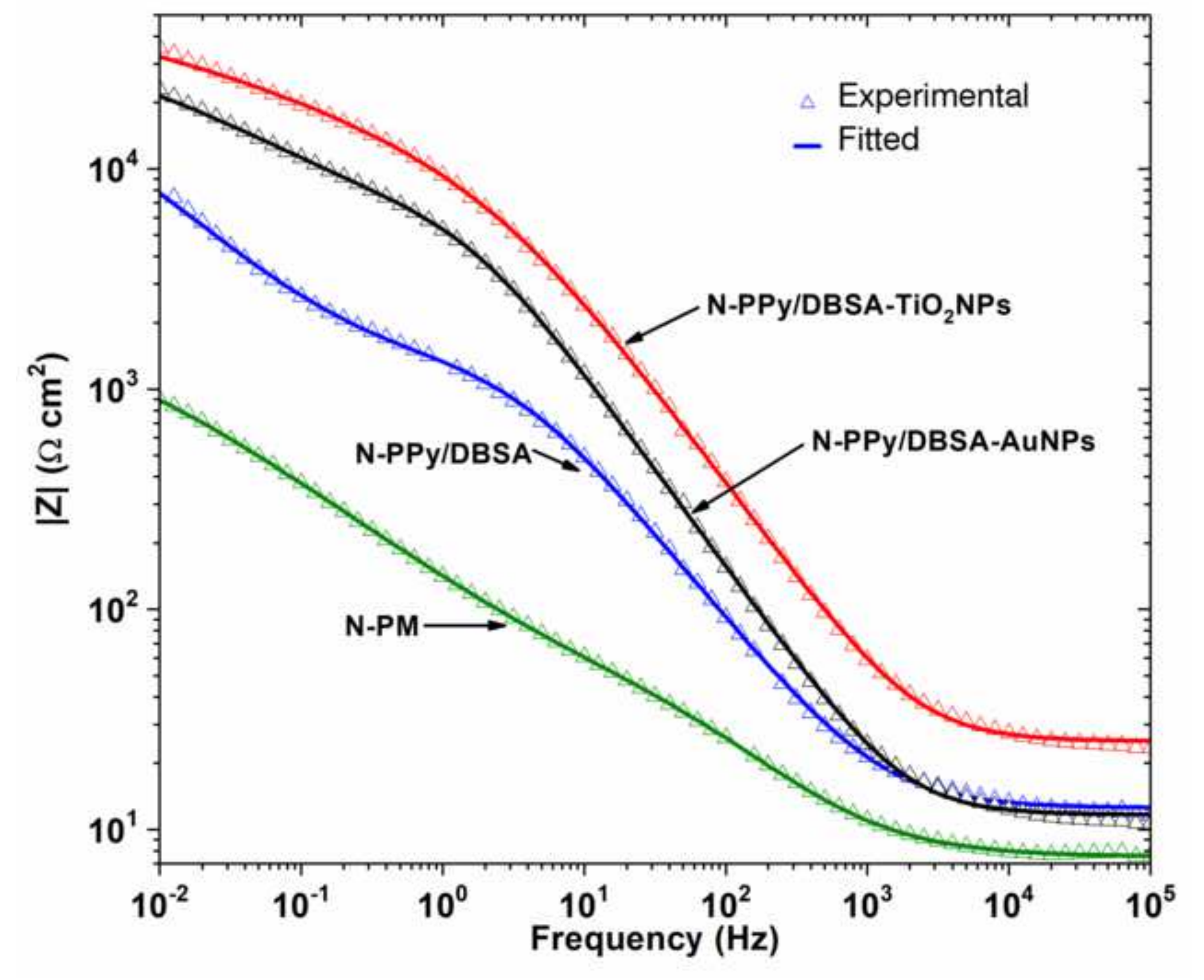

.


Click here to download high resolution image

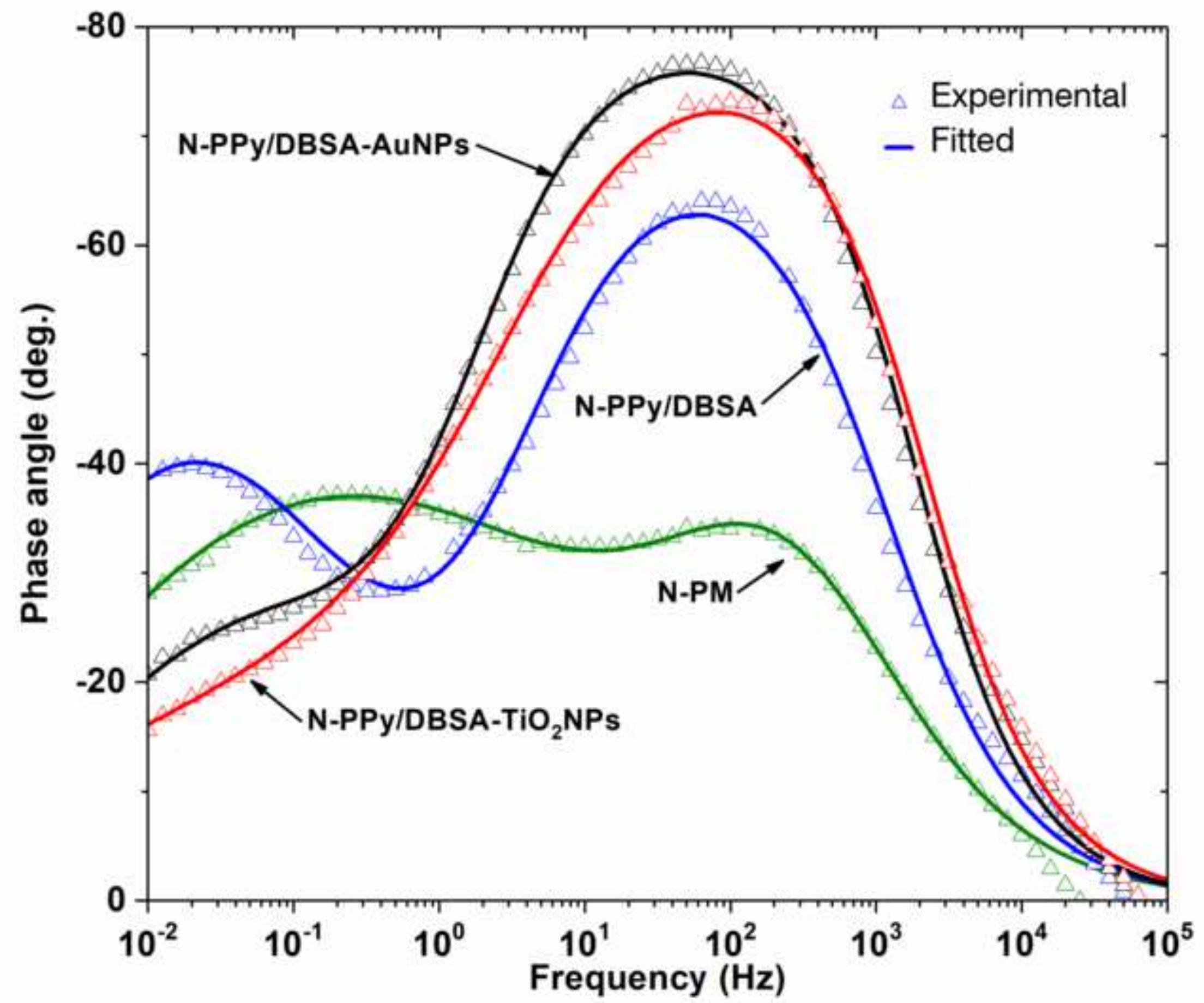


Click here to download high resolution image

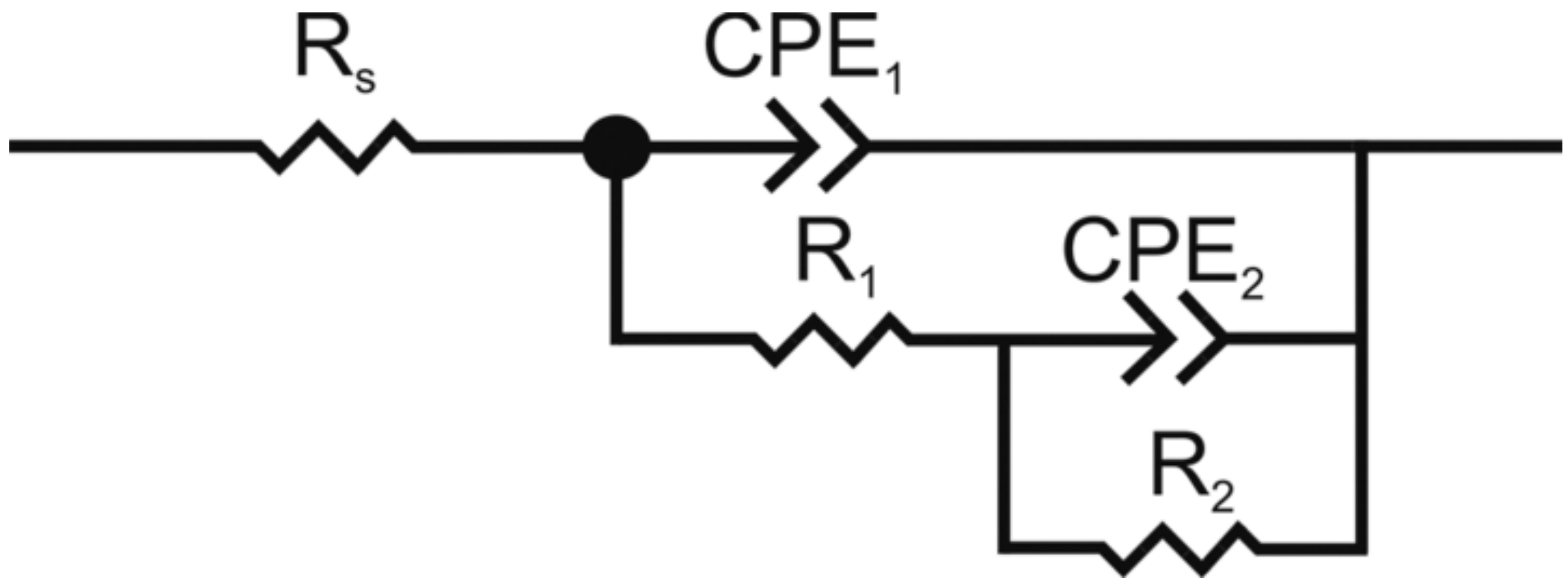




\section{FIGURE CAPTIONS}

Figure 1. PPy/ DBSA film electrodeposition curves as a function of time by using (a) $\mathrm{CP}$, run at a current density of $0.02 \mathrm{~mA} / \mathrm{mm}^{2}$, (b) CA, run at a constant potential of 0.8 $\mathrm{V}_{\mathrm{Ag} / \mathrm{AgCl}}$ and (c) CA, effect of voltage PEDOT/PSS

Figure 2. Electrochemical behaviour of conducting polymer coatings. Effect of dopants in PPy films (a) OCP evolution, (b) anodic polarization measurements. Effect of the conducting polymer (c) anodic polarization curves and effect of substrate (d) PPy/DBSA and (e) PA/Oxalic coated and uncoated samples.

Figure 3. SEM images of (a) PPy/DBSA film on nitrogen sintered sample, (b) and (c) PPy/DBSA film on wrought sample, (d) nitrogen sintered sample and (e) vacuum sintered sample.

Figure 4. Electrodeposition curves using CP a) PPy/DBSA-AuNPs nanocomposites and (b) PPy/DBSA-TiO ${ }_{2} \mathrm{NPs}$ nanocomposites.

Figure 5. SEM images of (a) and (b) PPy/DBSA-AuNPs nanocomposite (c) PPy/DBSA- $\mathrm{TiO}_{2} \mathrm{NPs}$ nanocomposite. TEM image of (d) PPy/DBSA-TiO $2 \mathrm{NPs}$ nanocomposite. All deposited on nitrogen sintered samples.

Figure 6. Potentiodynamic polarization curves of (a) coated and uncoated nitrogen sintered samples, (b) PPy/DBSA-AuNPs nanocomposite coated samples and (c) $\mathrm{PPy} / \mathrm{DBSA}-\mathrm{TiO}_{2} \mathrm{NPs}$ nanocomposite coated samples.

Figure 7. Nyquist (a) and Bode plots (b) of uncoated and coated nitrogen sintered samples. Results of the fitting to the equivalent electric circuit (c) are included. 


\section{FIGURE CAPTIONS}

Figure 1. PPy/ DBSA film electrodeposition curves as a function of time by using (a) $\mathrm{CP}$, run at a current density of $0.02 \mathrm{~mA} / \mathrm{mm}^{2}$ and (b) $\mathrm{CA}$, run at a constant potential of $0.8 \mathrm{~V}_{\mathrm{Ag} / \mathrm{AgCl} \text {. }}$

Figure 2. Electrochemical behaviour of conducting polymer coatings. Effect of dopants in PPy films (a) OCP evolution, (b) anodic polarization measurements. Effect of the conducting polymer (c) anodic polarization curves and (d) PPy/DBSA coated and uncoated samples.

Figure 3. SEM images of (a) PPy/DBSA film on nitrogen sintered sample, (b) and (c) PPy/DBSA film on wrought sample, (d) nitrogen sintered sample and (e) vacuum sintered sample.

Figure 4. Electrodeposition curves using chrono-potentiometry a) PPy/DBSA-AuNPs nanocomposites and (b) PPy/DBSA-TiO ${ }_{2} \mathrm{NPs}$ nanocomposites.

Figure 5. SEM images of (a) and (b) PPy/DBSA-AuNPs nanocomposite (c) PPy/DBSA- $\mathrm{TiO}_{2} \mathrm{NPs}$ nanocomposite. TEM image of (d) PPy/DBSA-TiO $2 \mathrm{NPs}$ nanocomposite. All deposited on nitrogen sintered samples.

Figure 6. Potentiodynamic polarization curves of (a) coated and uncoated nitrogen sintered samples, (b) PPy/DBSA-AuNPs nanocomposite coated samples and (c) PPy/DBSA-TiO 2 NPs nanocomposite coated samples. 


\section{Suggested referees}

- Prof. Dr. S. Virtanen (Department of Materials Science, WW4-LKO, University of Erlangen-Nuremberg, Germany).Virtanen@ww.uni-erlangen.de. She is an expert in electrodeposited films technology and in their application as corrosion protection

- Prof. Farzad Nasirpour (Faculty of Materials Engineering, Sahand University of Technology, Tabriz 51335-1996, Iran): Nasirpouri@sut.ac.ir. He is a well-recognized expert in thin films and nanoparticles for surface modification.

- Prof. Dra. Carmel B. Breslin (Department of Chemistry, Maynooth University, Ireland). Carmel.Breslin@mu.ie. She is a well-recognized expert in conductive polymer to corrosion protection. 


\section{CREDIT AUTHOR STATEMENT}

The manuscript was written through contributions of all authors. All authors have given approval to the final version of the manuscript.

C. García Cabezón.: Conceptualization; Data curation; Methodology; Formal analysis; Investigation; original draft; Writing - review \& editing. M. L. Rodriguez Mendez: Project administration; Original draft; Funding acquisition. Investigation; Coral Salvo Comino: Investigation. Celia García Henandez: Investigation. F. Martín Pedrosa. Conceptualization. Data curation. Formal analyisis, Sofware. Supervision. Original draft. 


\section{Declaration of interests}

$\bigotimes$ The authors declare that they have no known competing financial interests or personal relationships that could have appeared to influence the work reported in this paper.

$\square$ The authors declare the following financial interests/personal relationships which may be considered as potential competing interests:

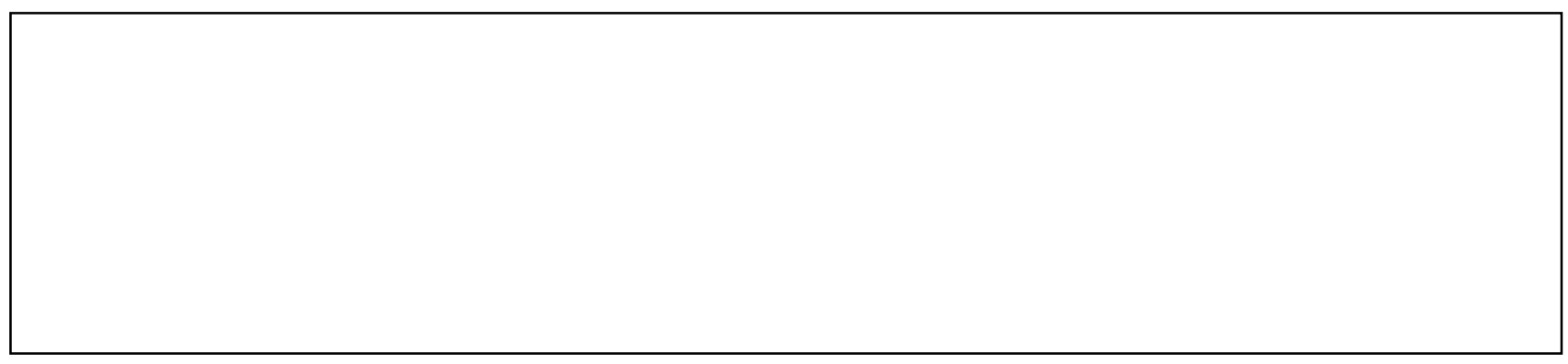

